\title{
Fractional-Order Model Predictive Frequency Control of an Islanded Microgrid
}

\author{
Min-Rong Chen ${ }^{1}$, Guo-Qiang Zeng ${ }^{2, *}$, Yu-Xing Dai ${ }^{2}$, Kang-Di Lu ${ }^{3, *}$ and Da-Qiang Bi 4 \\ 1 School of Computer, South China Normal University, Guangzhou 510631, China; 20151044@m.scnu.edu.cn \\ 2 National-Local Joint Engineering Laboratory of Digitalize Electrical Design Technology, Wenzhou University, \\ Wenzhou 325035, China; yxdai@hnu.edu.cn \\ 3 Department of Automation, College of Information Sciences and Technology, Donghua University, \\ Shanghai 201620, China \\ 4 State Key Laboratory of Power Systems and Department of Electrical Engineering, Tsinghua University, \\ Beijing 100084, China; bidaqiang@tsinghua.edu.cn \\ * Correspondence: zenggq@wzu.edu.cn or zeng.guoqiang5@gmail.com (G.Q.Z.); \\ 2161244@mail.dhu.edu.cn (K.D.L.); Tel.: +86-159-6740-5738 (G.Q.Z.); +86-188-1728-7280 (K.D.L.)
}

Received: 12 December 2018; Accepted: 24 December 2018; Published: 28 December 2018

\begin{abstract}
Optimal frequency control of an islanded microgrid has been a challenging issue in the research field of microgrids. Recently, fractional-order calculus theory and some related control methods have attempted to handle this issue. In this paper, a novel fractional-order model predictive control (FOMPC) method is proposed to achieve the optimal frequency control of an islanded microgrid by introducing a fractional-order integral cost function into model predictive control (MPC) algorithm. Firstly, a discrete state-space model is derived for the optimal frequency control problem of an islanded microgrid. Afterward, a fractional-order integral cost function is designed to guide the FOMPC algorithm to obtain optimal control law by borrowing the Grünwald-Letnikov (GL) definition of fractional order calculus. Six simulation studies have been carried out to illustrate the superiority of FOMPC to conventional MPC under dynamical load disturbances, perturbed system parameters and random dynamical power fluctuation of wind turbines.
\end{abstract}

Keywords: optimal frequency control; islanded microgrid; fractional-order calculus; model predictive control; cost function

\section{Introduction}

In the past decade, microgrids have been widely studied because of their potential environmental and economic benefits in regard to the integration distributed energy resources, especially renewable energy systems [1-3]. Due to the different types of distributed energy resources, dynamical load characteristics, power quality constraints, and perturbed system parameters, how to optimize control of a microgrid, for it to operate well under grid-connected and islanded modes, has been a challenging issue [4-6]. When a microgrid is islanded, an optimal controller should be designed to minimize the frequency deviations. In recent years, some research works have been reported related to the optimal frequency control issue of an islanded microgrid [7-10], but most works have focused on proportional-integral-derivative (PID) control method and its different kinds of improved versions based on intelligent optimization algorithms.

As one of the most widely-applied control methods in industry, model predictive control (MPC) ranks second only after PID control algorithm [11]. Recently, MPC has been extended to solve the optimal load frequency control (LFC) problems of power systems [12-16] and operation optimization issues of microgrids [17-20]. Especially, it should be noted that there are some existing works regarding 
MPC-based frequency control of microgrids [12,19-23]. Reference [12] developed a MPC-based coordinated load frequency control method for a microgrid under the condition regarding varied number of electric vehicles. By introducing a rule-based fuzzy controller to dynamically tune the weighting parameter used in cost function, a fuzzy MPC is proposed for the optimal LFC issue of an isolated microgrid [21]. In Reference [22], a MPC method is developed to implement the torque compensation of each wind turbine generator for the optimal frequency control of an isolated grid. Recently-reported work [23] focuses on a conventional MPC-based optimal frequency control method in terms of a traditional integer-order cost function for a standalone microgrid. The simulation results have illustrated the superiority of MPC to traditional proportional-integral (PI) controller.

On the other hand, fractional-order control theories and applications of traditional integer-order and fractional-order systems have attracted increasing attention over the past two decades [24]. The fractional-order PI/PID control algorithm has been considered as one of the most widely and successfully used methods in complex systems, such as servo systems [25,26], a nonlinear vertical tank system [27], electric balance vehicle system [28], an induction motor drive system [29], permanent magnetic synchronous generator [30], automatic voltage regulator systems [31], single-area delayed power systems [32], and multi-area interconnected power systems [33]. One particular concern is the fractional-order frequency control of an isolated microgrid. Multi-objective extremal optimization algorithm has been adopted to optimize the fractional-order PID frequency controller for islanded microgrids [34]. Additionally, some MPC or fractional-order MPC methods have been developed for traditional integer-order or fractional-order systems [35-42]. However, to the best knowledge of the authors, few works regarding the fractional-order model predictive frequency control of islanded microgrids have been reported so far.

As one of the most important applications concerning fractional-order calculus theory in single processing and optimal control areas, a novel fractional-order integral performance index has been introduced as an improved cost function to improve the system performance. As a seminal research work, Romero et al. [43] proposed a new type of arbitrary real-order integral cost function for infinite impulse response filter design. The work in Reference [44] used a real-coded genetic algorithm to optimize the weighting matrices used in Linear Quadratic Regulator (LQR) systems by designing a fractional-order integral cost function. Furthermore, Romero et al. [36] also introduced a fractional-order definite integration operator into the cost function and then presented a fractional-order generalized predictive control method to deal with the optimal speed control issue for gasoline-propelled cars. Moreover, Bigdeli [37] designed a genetic algorithm-based fractional-order predictive functional controller (FOPFC) for fractional-order systems by adopting a fractional-order integral cost function. In Reference [45], Grünwald-Letnikov (GL) definition of fractional-order calculus theory has also been introduced in the cost function of a FOPFC to enhance the performance of fractional-order industrial processes. In addition, Zhang el al. [40] proposed a fractional-order MPC method for the optimal temperature control issue of industrial heating furnaces by using a fractional-order cost function based on the GL definition. These above research works have illustrated the superiority of fractional-order integral cost functions to conventional integer-order ones in the applications of signal processing, optimal LQR design and optimal predictive functional control.

Inspired by the aforementioned descriptions, this work proposes a fractional-order MPC, termed the FOMPC method, to achieve optimal frequency control performance for an islanded microgrid by introducing a fractional-order integral cost function into a model predictive control (MPC) algorithm. Firstly, an extended discrete state-space model is derived for the optimal frequency control problem of an islanded microgrid by considering some disturbance variables. Then, a fractional-order integral cost function is designed to guide the model predictive control algorithm to obtain optimal control law by borrowing the GL definition of fractional-order calculus theory. Six simulation studies on a typical microgrid have been carried out to illustrate the superiority of FOMPC over a conventional MPC under dynamical load disturbances, perturbed system parameters and the dynamic fluctuation of wind. 
The major contribution of this paper can be summarized by the following three points:

(1) A fractional-order model predictive control (FOMPC) method is proposed for the optimal frequency control problem of an islanded microgrid for the first time.

(2) The proposed FOMPC method extends the traditional quadratic cost function and introduces a fractional-order integral cost function based on the GL fractional-order integral definition.

(3) In comparison with the conventional integer-order MPC algorithm, the proposed FOMPC can improve the performance of an islanded microgrid especially under several conditions of load disturbance, parameter uncertainty and random dynamical fluctuations of wind turbines.

The rest of this work is structured as follows. The discrete-time space model of an islanded microgrid is derived in Section 2. Section 3 proposes the FOMPC-based frequency control method. In Section 4, the simulation results for six cases and the effects of two fractional-order parameters on frequency control performance will be provided. Finally, the conclusions and some open issues are presented in Section 5.

\section{Discrete-Time Space Model}

The block diagram of the frequency control issue for an islanded microgrid with a FOMPC controller is shown in Figure 1. For convenient, fair comparison with the traditional integer-order MPC method [23], the system model of the microgrid tested in this paper is the same as that in Reference [23]. The transfer functions and related system parameters of the distributed generations in an islanded microgrid under study are described in Table 1 . The distributed subsystems in this microgrid under study include a wind turbine generator (WTG), diesel-engine generator (DEG), and energy storage system (ESS). As mentioned in Chapter 11 of Reference [46], EES can be considered as a fuel cell (FC)/battery, flywheel energy storage system (FESS), superconducting magnetic energy storage (MESS) or a combination of these. Here, we adopt FESS as the ESS in the microgrid under study.

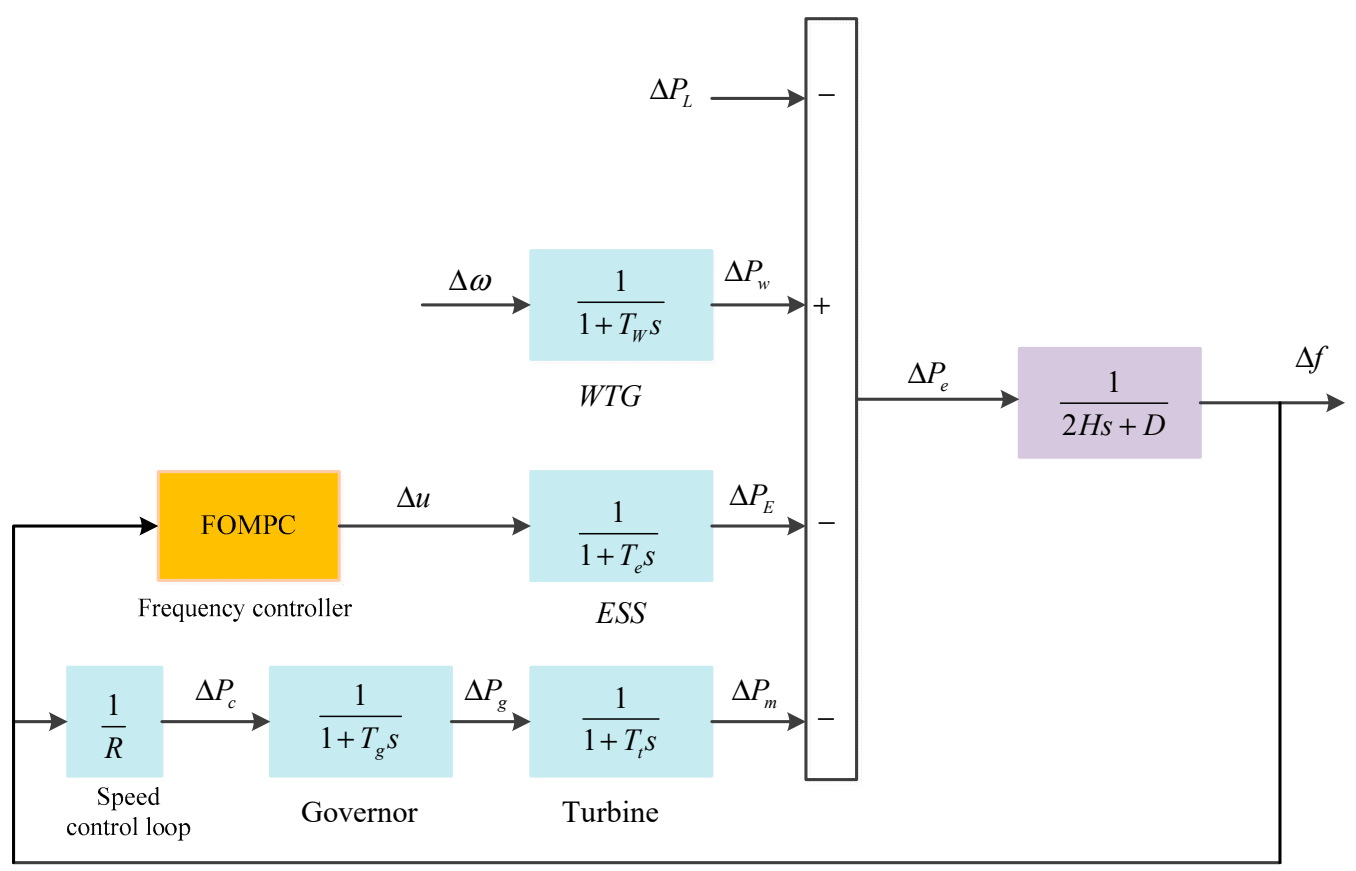

Figure 1. The block diagram of an islanded microgrid under study with a FOMPC-based frequency controller. 
Table 1. The transfer functions and the related parameters used in each subsystem.

\begin{tabular}{ccc}
\hline Subsystem & Transfer Function & Parameters \\
\hline WTG & $\frac{1}{1+T_{W} s}$ & $T_{W}=1.5 \mathrm{~s}$ \\
Speed control loop & $\frac{1}{R}$ & $R=3 \mathrm{~Hz} / \mathrm{pu}$ \\
Governor & $\frac{1}{\left(1+T_{g} s\right)}$ & $T_{g}=0.08 \mathrm{~s}$ \\
Turbine & $\frac{1}{\left(1+T_{t} s\right)}$ & $T_{t}=4 \mathrm{~s}$ \\
Microgrid system & $\frac{1}{2 H s+D}$ & $D=0.015 \mathrm{pu} / \mathrm{Hz}, \mathrm{H}=1 / 12 \mathrm{pu} \cdot \mathrm{s}$ \\
ESS & $\frac{1}{1+T_{e} s}$ & $T_{e}=0.1 \mathrm{~s}$ \\
\hline
\end{tabular}

Define $\mathbf{x}(t)=\left[\Delta P_{E}(t), \Delta P_{w}(t), \Delta P_{g}(t), \Delta P_{m}(t), \Delta f(t)\right]^{T}, \mathbf{u}(t)=\Delta u(t), \mathbf{w}(t)=\left[\Delta w(t), \Delta P_{L}(t)\right]^{T}$, and $\mathbf{y}(t)$ $=\Delta f(t)$ in the microgrid under study. Here, $\Delta P_{E}(t), \Delta P_{w}(t), \Delta P_{g}(t)$, and $\Delta P_{m}(t)$ represent the power deviations of ESS, WTG, governor, and turbine, respectively. $\Delta u(t)$ represents the incremental form of control signal, $\Delta w(t)$ represents the input power fluctuation of WTG, $\Delta P_{L}(t)$ is the load fluctuation, and $\Delta P_{e}(t)$ represents the power deviation of the whole microgrid system, i.e., $\Delta P_{e}(t)=\Delta P_{w}(t)-\Delta P_{E}(t)$ $-\Delta P_{m}(t)-\Delta P_{L}(t)$. The continuous-time state space model for the frequency control of an islanded microgrid is defined by Equations (1) and (2).

$$
\begin{gathered}
\dot{\mathbf{x}}(t)=\mathbf{A}_{c} \mathbf{x}(t)+\mathbf{B}_{c 1} \mathbf{u}(t)+\mathbf{B}_{c 2} \mathbf{w}(t) \\
\mathbf{y}(t)=\mathbf{C} \mathbf{x}(t)
\end{gathered}
$$

where $\mathbf{A}_{c}, \mathbf{B}_{c 1}, \mathbf{B}_{c 2}$, and $\mathbf{C}$ are defined as follows:

$$
\begin{gathered}
\mathbf{A}_{c}=\left[\begin{array}{ccccc}
-\frac{1}{T_{e}} & 0 & 0 & 0 & 0 \\
0 & -\frac{1}{T_{W}} & 0 & 0 & 0 \\
0 & 0 & -\frac{1}{T_{g}} & 0 & \frac{1}{R T_{g}} \\
0 & 0 & \frac{1}{T_{t}} & -\frac{1}{T_{t}} & 0 \\
-\frac{1}{2 H} & \frac{1}{2 H} & 0 & -\frac{1}{2 H} & -\frac{D}{2 H}
\end{array}\right] \\
\mathbf{B}_{c 1}=\left[\begin{array}{ccccc}
\frac{1}{T_{e}} & 0 & 0 & 0 & 0
\end{array}\right]^{T} \\
\mathbf{B}_{c 2}=\left[\begin{array}{ccccc}
0 & \frac{1}{T_{W}} & 0 & 0 & 0 \\
0 & 0 & 0 & 0 & -\frac{1}{2 H}
\end{array}\right]^{T} \\
\mathbf{C}=\left[\begin{array}{llllc}
0 & 0 & 0 & 0 & 1
\end{array}\right]^{T}
\end{gathered}
$$

The discrete-time state space model of an islanded microgrid is obtained by the following equations:

$$
\begin{gathered}
\mathbf{x}(k+1)=\mathbf{A}_{d} \mathbf{x}(k)+\mathbf{B}_{d 1} \mathbf{u}(k)+\mathbf{B}_{d 2} \mathbf{w}(k) \\
\mathbf{y}(k)=\mathbf{C}_{d} \mathbf{x}(k)
\end{gathered}
$$

where $\mathbf{A}_{d}=e^{\mathbf{A}_{c} T_{s}}, \mathbf{B}_{d 1}=\int_{0}^{T_{s}} e^{A_{c} t} B_{c 1} d t, \mathbf{B}_{d 2}=\int_{0}^{T_{s}} e^{A_{c} t} B_{c 2} d t$, and $T_{s}$ is the sampling period. 
It should be noted, the discrete-time space model can also be derived by a similar method for a more complex microgrid system, with more types of distributed generations, e.g., hydric, thermal, or photovoltaic generations. The only difference is that $\mathbf{x}(t), \mathbf{u}(t), \mathbf{w}(t), \mathbf{A}_{c}, \mathbf{B}_{c 1}, \mathbf{B}_{c 2}$, and $\mathbf{C}$ in Equations (1) and (2) should be redefined according to the topology structure and block diagram of a new microgrid system.

\section{FOMPC-Based Optimal Frequency Control Method}

In this section, we propose a novel FOMPC method for the optimal frequency control issue of an islanded microgrid.

Firstly, let us define the predictive output vector as $\mathbf{Y}_{P}(k)=\left(\begin{array}{c}\mathbf{y}(k \mid k) \\ \vdots \\ \mathbf{y}(k+P-1 \mid k)\end{array}\right)_{P \times N_{y}}$, the predictive state vector as $\mathbf{X}(k)=\left(\begin{array}{c}\mathbf{x}(k) \\ \vdots \\ \mathbf{x}(k+P-1)\end{array}\right)_{P \times N_{x}}$, the predictive disturbance vector as $\mathbf{W}(k)=\left(\begin{array}{c}\mathbf{w}(k) \\ \vdots \\ \mathbf{w}(k+P-1)\end{array}\right)_{P \times N_{w}}$, the predictive control vector as $\Delta \mathbf{U}(k)=$ $\left(\begin{array}{c}\Delta \mathbf{u}(k) \\ \vdots \\ \Delta \mathbf{u}(k+M-1)\end{array}\right)_{M \times N_{u}}$, where $N_{x}, N_{y}, N_{u}$ and $N_{w}$ are the dimensions of $\mathbf{x}(k), \mathbf{y}(k), \mathbf{u}(k)$ and $\mathbf{w}(k)$, respectively. Then, the predictive output vector $\mathbf{Y}_{P}(k)$ is computed according to Equations (9)-(13):

$$
\begin{aligned}
& \mathbf{Y}_{P}(k)=\mathbf{G X}(k)+\mathbf{H u}(k-1)+\mathbf{E} \mathbf{W}(k)+\mathbf{F} \Delta \mathbf{U}(k) \\
& \mathbf{G}=\left[\begin{array}{c}
\mathbf{C}_{d} \\
\mathbf{C}_{d} \mathbf{A}_{d} \\
\vdots \\
\mathbf{C}_{d} \mathbf{A}_{d}^{P-1}
\end{array}\right] \\
& \mathbf{H}=\left[\begin{array}{c}
0 \\
\mathbf{C}_{d} \mathbf{B}_{d 1} \\
\vdots \\
\mathbf{C}_{d}\left\{\sum_{j=0}^{P-2} A_{d}^{j}\right\} \mathbf{B}_{d 1}
\end{array}\right] \\
& \mathbf{E}=\left[\begin{array}{c}
0 \\
\mathbf{C}_{d} \mathbf{B}_{d 2} \\
\vdots \\
\mathbf{C}_{d}\left\{\sum_{j=0}^{P-2} A_{d}^{j}\right\} \mathbf{B}_{d 2}
\end{array}\right] \\
& \mathbf{F}=\left[\begin{array}{cccc}
\mathbf{0} & \mathbf{0} & \cdots & \mathbf{0} \\
\mathbf{C}_{d} \mathbf{B}_{d 1} & \mathbf{0} & \cdots & \mathbf{0} \\
\vdots & \vdots & \ddots & \vdots \\
\mathbf{C}_{d}\left\{\sum_{j=0}^{P-2} A_{d}^{j}\right\} \mathbf{B}_{d 1} & \mathbf{C}_{d}\left\{\sum_{j=0}^{P-1} A_{d}^{j}\right\} \mathbf{B}_{d 1} & \cdots & \mathbf{C}_{d}\left\{\sum_{j=0}^{P-M-1} A_{d}^{j}\right\} \mathbf{B}_{d 1}
\end{array}\right]\left[\begin{array}{cccc}
\mathbf{1} & \mathbf{0} & \cdots & \mathbf{0} \\
\mathbf{1} & \mathbf{1} & \cdots & \mathbf{0} \\
\vdots & \vdots & \ddots & \vdots \\
\mathbf{1} & \mathbf{1} & \cdots & \mathbf{1}
\end{array}\right]_{M \times M}
\end{aligned}
$$


where $P$ and $M$ are the prediction horizon and the control horizon, respectively.

Reference trajectory $\mathbf{y}_{r}(k+p \mid k)$ used in this paper is defined as follows [11]:

$$
\mathbf{y}_{r}(k+p \mid k)=\eta^{p} \mathbf{y}(k)+\left(1-\eta^{p}\right) \mathbf{c}(k), p=0, \ldots(P-1)
$$

where $\eta$ represents a soften factor, and $\mathbf{c}(k)$ represents the set value of system output. In terms of vector-based form, Equation (14) can be also reformulated using the following equation:

$$
\mathbf{Y}_{r}(k)=\left(\begin{array}{c}
\mathbf{y}_{r}(k \mid k) \\
\cdots \\
\mathbf{y}_{r}(k+P-1 \mid k)
\end{array}\right)_{P \times N_{y}}
$$

From the perspective of traditional MPC, the optimal frequency control issue of an islanded microgrid is formulated as follows:

$$
\begin{gathered}
J(k)=\min \left\{\left(\mathbf{Y}_{P}(k)-\mathbf{Y}_{r}(k)\right)^{T} \mathbf{Q}\left(\mathbf{Y}_{P}(k)-\mathbf{Y}_{r}(k)\right)+(\Delta \mathbf{U}(k))^{T} \mathbf{R}(\Delta \mathbf{U}(k))\right\} \\
\text { s.t. } \quad \mathbf{u}_{\min } \leq \mathbf{u}(k) \leq \mathbf{u}_{\max } \\
\Delta \mathbf{u}_{\min } \leq \Delta \mathbf{u}(k) \leq \Delta \mathbf{u}_{\max } \\
\mathbf{y}_{\min } \leq \mathbf{y}(k) \leq \mathbf{y}_{\max }
\end{gathered}
$$

where $\mathbf{Q}$ is a weight vector to adjust the performance of predicted errors, and $\mathbf{R}$ is another weight vector for the future control vector. $\mathbf{u}_{\min }, \Delta \mathbf{u}_{\min }$, and $\mathbf{y}_{\min }$ are defined as the lower limits of $\mathbf{u}(k), \Delta \mathbf{u}(k)$, and $\mathbf{y}(k)$, respectively, and $\mathbf{u}_{\max }, \Delta \mathbf{u}_{\max }$, and $\mathbf{y}_{\max }$ are the corresponding upper limits.

For an islanded microgrid, Figure 2 represents a schematic diagram of FOMPC-based optimal frequency control method. More specifically, by introducing the GL definition of fractional order calculus [43] into Equation (16), a fractional-order integral cost function $J_{F O}(\mathrm{k})$ is approximated by Equations (18)-(21). The detailed derivation process from Formulation (16) to Formulation (18) can be found in Reference [43].

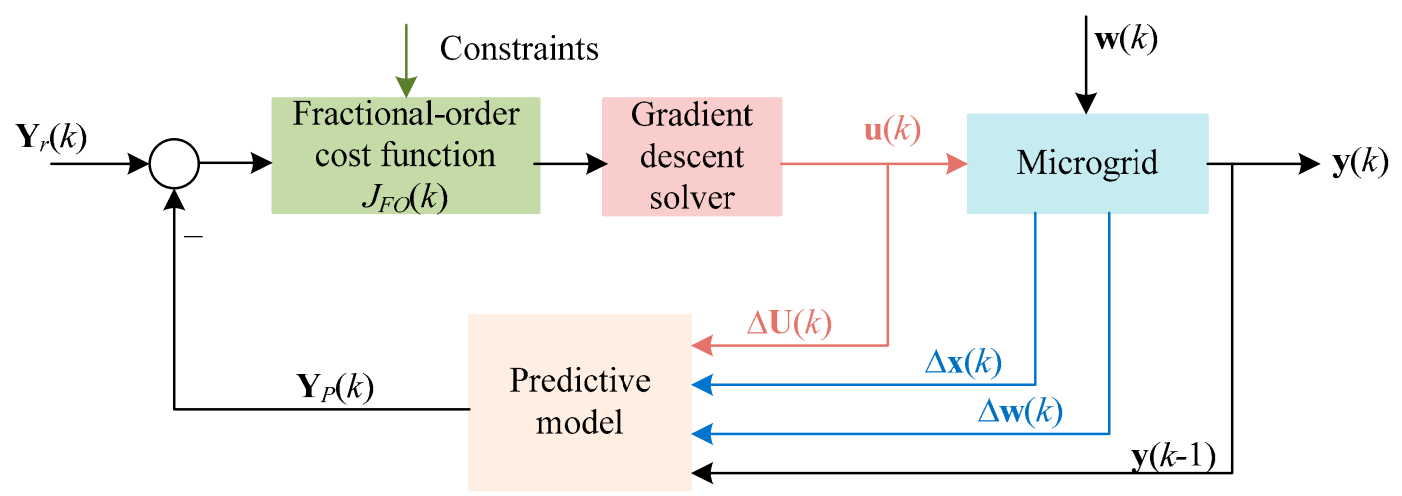

Figure 2. The schematic diagram of FOMPC-based optimal frequency control method.

$$
\begin{array}{r}
J(k) \cong J_{F O}(k)=\left(\mathbf{Y}_{P}(k)-\mathbf{Y}_{r}(k)\right)^{T} \mathbf{Q}\left(\Lambda\left(T_{s}, \gamma\right)\right)\left(\mathbf{Y}_{P}(k)-\mathbf{Y}_{r}(k)\right)+(\Delta \mathbf{U}(k))^{T} \mathbf{R}\left(\Lambda\left(T_{s}, \beta\right)\right)(\Delta \mathbf{U}(k)) \\
\Lambda\left(T_{s}, \gamma\right)=T_{s} \operatorname{diag}\left(m_{P-1}, m_{P-2}, \ldots, m_{1}, m_{0}\right) \\
m_{j}=\lambda_{j}^{(-\gamma)}-\lambda_{j-(P-1)}^{(-\gamma)} \\
\lambda_{j}^{(-\gamma)}= \begin{cases}(1-(1-\gamma) / j) \lambda_{j-1}^{(-\gamma)}, & j>0 ; \\
1, & j=0 ; \\
0, & j<0 .\end{cases}
\end{array}
$$


By combining Equations (9)-(13), the fractional-order integral cost function described by Equation (18) is reformulated as follows:

$$
\begin{gathered}
J_{F O}(k)=\left(\mathbf{G X}(k)+\mathbf{H} \mathbf{U}(k-1)+\mathbf{E W}(k)-\mathbf{Y}_{r}(k)\right)^{T} \mathbf{Q}\left(\Lambda\left(T_{s}, \gamma\right)\right)\left(\mathbf{G X}(k)+\mathbf{H} \mathbf{U}(k-1)+\mathbf{E W}(k)-\mathbf{Y}_{r}(k)\right)+ \\
(\Delta \mathbf{U}(k))^{T} \mathbf{K} \Delta \mathbf{U}(k)-(\Delta \mathbf{U}(k))^{T} \mathbf{T} \\
\mathbf{K}=\mathbf{F}^{T} \mathbf{Q}\left(\Lambda\left(T_{s}, \gamma\right)\right) \mathbf{F}+\mathbf{R}\left(\Lambda\left(T_{s}, \beta\right)\right) \\
\mathbf{T}=2 \mathbf{F}^{T} \mathbf{Q}\left(\Lambda\left(T_{s}, \gamma\right)\right)\left(\mathbf{G X}(k)+\mathbf{H} \mathbf{U}(k-1)+\mathbf{E W}(k)-\mathbf{Y}_{r}(k)\right)
\end{gathered}
$$

where $\beta$ and $\gamma$ are the fractional-order parameters.

Based on the gradient descent method, we can obtain the following optimal control vector $\mathbf{u}(k)$ :

$$
\begin{gathered}
\mathbf{u}(k)=\mathbf{u}(k-1)+\Delta \mathbf{u}(k) \\
\Delta \mathbf{u}(k)=\left(\begin{array}{cc}
\mathbf{I}_{N_{u}} & \mathbf{0}_{N_{u} \times(P-1)}
\end{array}\right) \Delta \mathbf{U}_{o p t}(k) \\
\Delta \mathbf{U}_{\text {opt }}(k)=\frac{1}{2} \mathbf{K}^{-1} \mathbf{T}
\end{gathered}
$$

where $\mathbf{I}_{N_{u}}$ represents an identity matrix with $\mathrm{N}_{\mathrm{u}}$ rows and $\mathrm{N}_{\mathrm{u}}$ columns.

The flowchart of the proposed FOMPC-based optimal frequency control method for an islanded microgrid is shown in Figure 3.

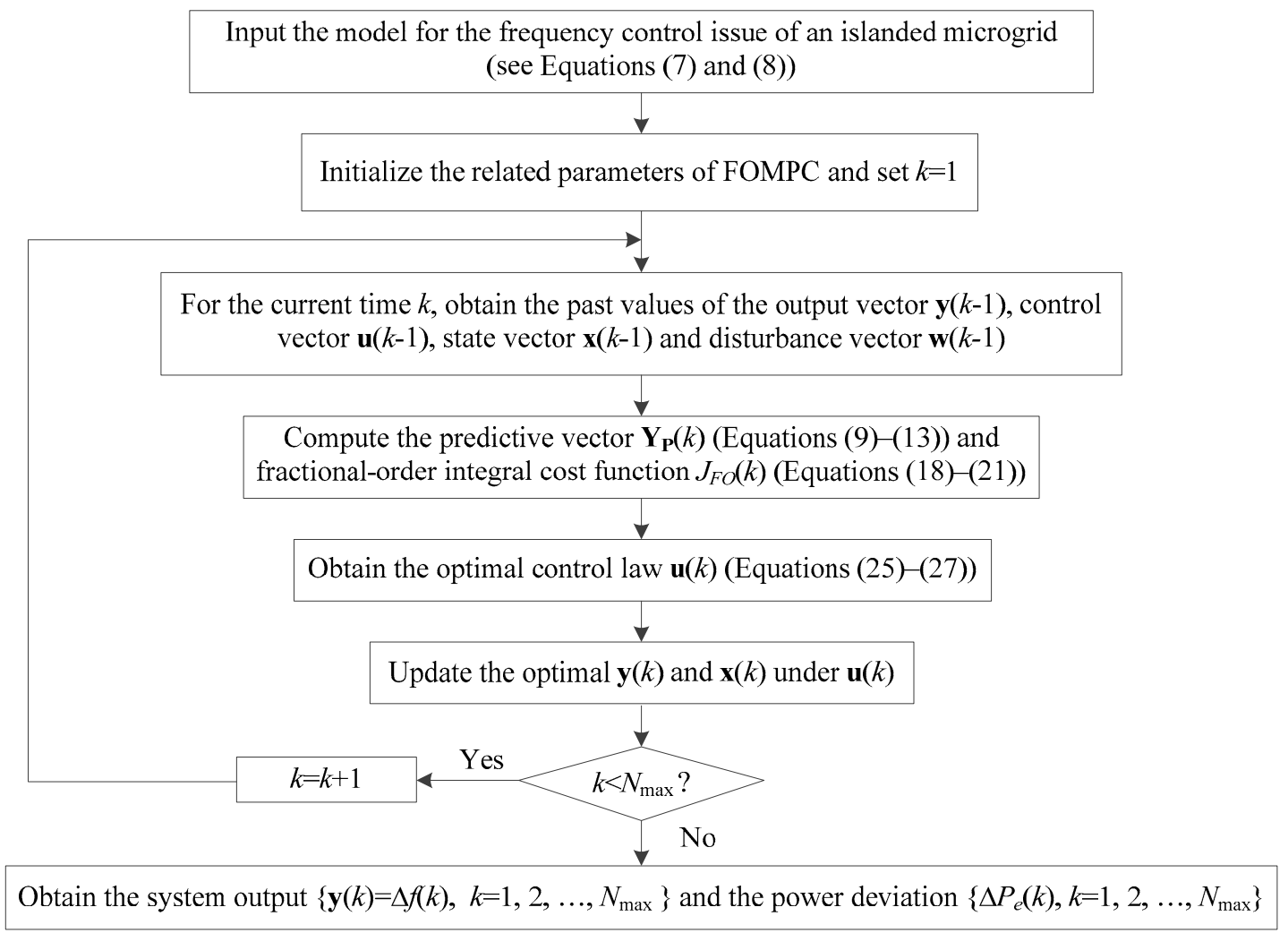

Figure 3. The flowchart of FOMPC-based optimal frequency control method for an islanded microgrid.

In conclusion, the detailed steps of the proposed FOMPC-based optimal frequency control method for an islanded microgrid are summarized as follows:

Step 1: Input a discrete-time state space model with sampling period $T_{S}$ for the frequency control issue of an islanded microgrid system described by Equations (7) and (8). 
Step 2: Initialize the algorithm parameters of FOMPC including maximum number of sampling times $N_{\max }, P, M, \mathbf{Q}, \mathbf{R}, \beta$ and $\gamma$, and set $k=1$.

Step 3: $\quad$ For the current time $k$, obtain $\mathbf{y}(k-1)=\Delta f(k-1), \mathbf{u}(k-1)=\Delta u(k-1), \mathbf{x}(k-1)=\left[\Delta P_{E}(k-\right.$ 1), $\left.\Delta P_{w}(k-1), \Delta P_{g}(k-1), \Delta P_{m}(k-1), \Delta f(k-1)\right]^{T}$ and $\mathbf{w}(k-1)=\left[\Delta w(k-1), \Delta P_{L}(k-1)\right]^{T}$.

Step 4: Obtain the predictive vector $\mathbf{Y}_{\mathbf{P}}(k)$ according to Equations (9)-(13) and fractional-order integral cost function $J_{F O}(k)$ by Equations (18)-(21).

Step 5: Compute the optimal control vector $\mathbf{u}(k)$ by Equations (25)-(27) based on gradient descent method.

Step 6: Update the optimal $\mathbf{y}(k)$ and $\mathbf{x}(k)$ under $\mathbf{u}(k)$.

Step 7: Set $k=k+1$, and repeat the loop from Step 4 to Step 7 until $k=N_{\max }$.

Step 8: Output $\left\{\mathbf{y}(k)=\Delta f(k), k=1,2, \ldots, N_{\max }\right\}$ and $\left\{\Delta P_{e}(k), k=1,2, \ldots, N_{\max }\right\}$.

\section{Simulation Results}

The simulation results in Reference [23] have illustrated the superiority of MPC to traditional PI controller for the optimal frequency control issue of an islanded microgrid. To make a fair comparison between the proposed FOMPC and traditional MPC method [23], simulation studies are carried out for the same microgrid system model, as shown in Figure 1 [23]. The parameters of system model are set as in Table 1. Six experiments are designed as Table 2 to demonstrate the superiority of FOMPC to the traditional integer-order MPC method under dynamical load disturbances, perturbed system parameters and random dynamical power fluctuation of wind turbines. The parameter settings for FOMPC and MPC are shown in Table 3. All the following simulation experiments have been performed by the aid of MATLAB 2014b software on a $2.50 \mathrm{GHz}$ PC with i7-6500U processor and 8GB RAM.

Table 2. The conditions of six experiments for an islanded microgrid.

\begin{tabular}{|c|c|}
\hline Experiment & Condition \\
\hline Case 1 & Normal system parameters, $\Delta P_{L}=0.02$ p.u. after $1 \mathrm{~s}$. \\
\hline Case 2 & Normal system parameters, dynamical fluctuations of $\Delta P_{L}$ \\
\hline Case 3 & Normal system parameters, random dynamical fluctuations of $\Delta w$. \\
\hline Case 4 & $\begin{array}{c}\left.\text { Perturbed system parameters, i.e., } T_{t}=0.6 \text { (increase } 50 \%\right), R=1.5(\text { decrease } 50 \%), H=0.0833 \\
\text { (decrease } 50 \%) \text {, dynamical fluctuations of } \Delta P_{L} .\end{array}$ \\
\hline Case 5 & $\begin{array}{c}\text { Perturbed system parameters, i.e., } T_{t}=0.6 \text { (increase } 50 \% \text { ), } R=1.5 \text { (decrease } 50 \% \text { ), } H=0.0833 \\
\text { (decrease } 50 \% \text { ), random dynamical fluctuations of } \Delta w .\end{array}$ \\
\hline Case 6 & $\begin{array}{l}\left.\left.\text { Perturbed system parameters, i.e., } T_{t}=0.6 \text { (increase } 50 \%\right), R=1.5 \text { (decrease } 50 \%\right), H=0.0833 \\
\quad(\text { decrease } 50 \%) \text {, dynamical fluctuations of } \Delta P_{L} \text {, random dynamical fluctuations of } \Delta w \text {. }\end{array}$ \\
\hline
\end{tabular}

Table 3. The parameters settings for FOMPC and MPC.

\begin{tabular}{cc}
\hline Algorithm & Parameters Setting \\
\hline MPC & $P=10, M=2, \mathbf{Q}=I_{P \times P}$, and $\mathbf{R}=0.1 I_{M \times M}$. \\
FOMPC & $P=7, M=2, \mathbf{Q}=I_{P \times P}, \mathbf{R}=I_{M \times M}, \gamma=\beta=6.2$. \\
\hline
\end{tabular}

\subsection{Case 1: Normal System Parameters and Step Load Fluctuations}

In case 1 , we consider the condition of normal system parameters of an islanded microgrid and $\Delta P_{L}=0.02$ p.u. after $1 \mathrm{~s}$. Figure 4 presents the comparative results of frequency deviation $\Delta f$, and power deviation $\Delta P_{e}$ obtained by FOMPC and MPC for an islanded microgrid under case 1. Obviously, the transient-state and steady-state responses of $\Delta f$ and $\Delta P_{e}$ obtained by FOMPC are better than those by MPC [23]. The performance of FOMPC and MPC methods is evaluated by the indices including the integral of absolute value of the error (IAE) for $\triangle f$ and $\Delta P_{e}$ denoted as $I A E_{1}$ and $I A E_{2}$, respectively, the overshoot of $\Delta f$ and $\Delta P_{e}$ denoted as $M_{p 1}$ and $M_{p 2}$, respectively, the rising time of $\Delta f$ and $\Delta P_{e}$ denoted as $t_{u 1}$ and $t_{u 2}$, respectively, the settling time of $\Delta f$ and $\Delta P_{e}$ denoted as $t_{s 1}$ and $t_{s 2}$, respectively, 
and the steady-state error of $\Delta f$ and $\Delta P_{e}$ denoted as $E_{s s 1}$ and $E_{s s 2}$, respectively. The $I A E_{1}$ and $I A E_{2}$ are defined as follows:

$$
\begin{gathered}
I A E_{1}=\sum_{k=1}^{N_{\max }}|\Delta f(k)| \\
I A E_{2}=\sum_{k=1}^{N_{\max }}\left|\Delta P_{e}(k)\right|
\end{gathered}
$$

Table 4 shows the performance comparison of FOEMPC and MPC for an islanded microgrid under case 1. Clearly, all the indices except $E s s_{1}$ obtained by FOMPC are better than those by MPC [23].

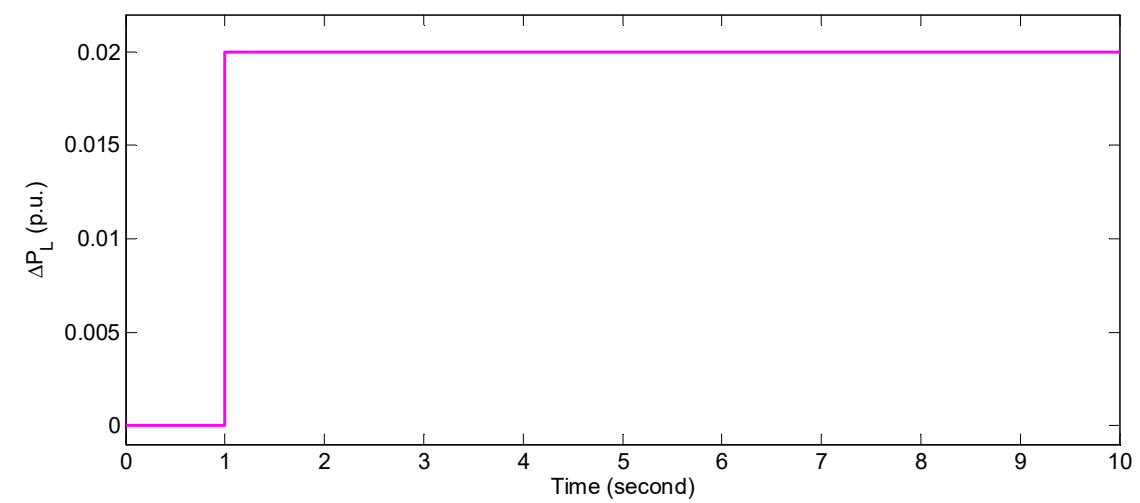

(a) $\triangle P_{L}$

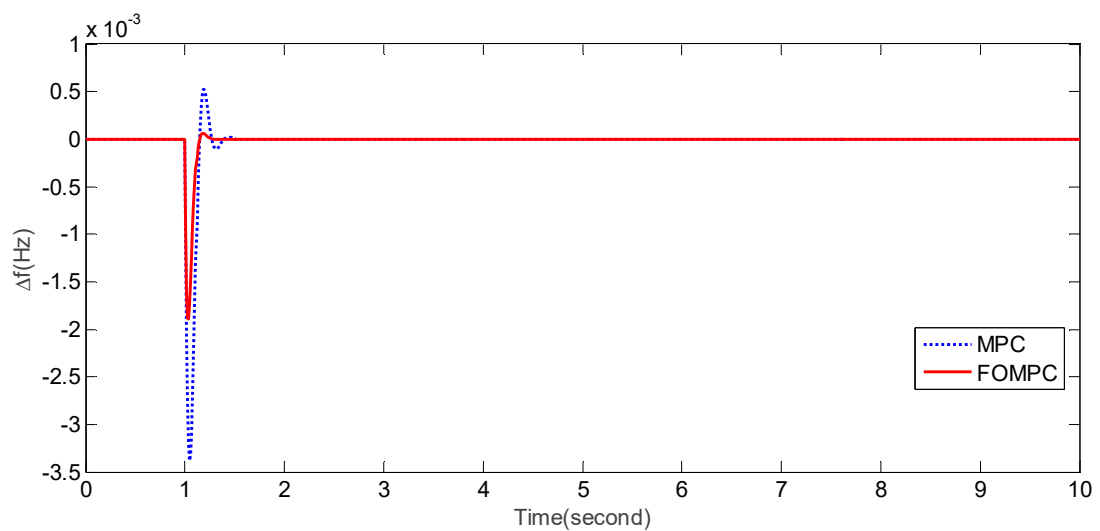

(b) $\Delta f$

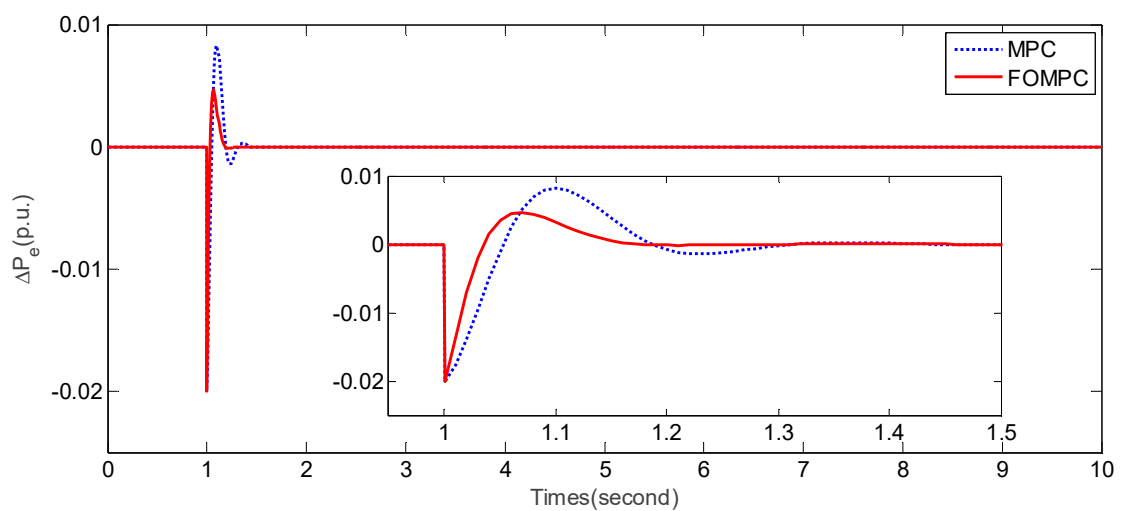

(c) $\triangle P_{e}$

Figure 4. Responses of $\Delta f$ and $\Delta P_{e}$ obtained by FOMPC and MPC under case 1. 
Table 4. Control performance indices obtained by FOMPC and MPC for an islanded microgrid under case 1 . The best values are marked in bold.

\begin{tabular}{|c|c|c|c|c|c|c|c|c|c|c|}
\hline Algorithm & $I A E_{1}$ & $M_{p 1}$ & $t_{u 1}$ & $t_{s 1}$ & $E_{s s 1}$ & $I A E_{2}$ & $M_{p 2}$ & $t_{u 2}$ & $t_{s 2}$ & $E_{s s 2}$ \\
\hline MPC & 0.0335 & $5.27 \times 10^{4}$ & 1.12 & 1.19 & $4.73 \times 10^{17}$ & 0.1793 & 0.0082 & 1.18 & 1.27 & $2.62 \times 10^{17}$ \\
\hline FOEMPC & 0.0141 & $5.96 \times 10^{5}$ & 1.08 & 1.18 & $5.19 \times 10^{17}$ & 0.0909 & 0.0047 & 1.05 & 1.14 & $2.36 \times 10^{17}$ \\
\hline
\end{tabular}

\subsection{Case 2: Normal System Parameters and Dynamical Load Fluctuations}

For case 2, the dynamical fluctuations of $\Delta P_{L}$ (e.g., Figure 5a) and normal system parameters are considered. Figure $5 \mathrm{~b}, \mathrm{c}$ compare $\Delta f$ and $\Delta P_{e}$ obtained by FOMPC and MPC for an islanded microgrid, respectively. From the perspective of quantitative comparison, the control performance of $\Delta f$ and $\triangle P_{e}$ obtained by FOMPC and MPC is evaluated by the indices including $I A E_{1}, I A E_{2}, I T A E_{1}, I T A E_{2}, I S E_{1}$, $I S E_{2}, I T S E_{1}$, and ITSE $E_{2}$. To be more specific, the ITAE $, I T A E_{2}, I S E_{1}, I S E_{2}, I T S E_{1}$, and ITSE 2 are defined as follows:

$$
\begin{aligned}
I T A E_{1} & =\sum_{k=1}^{N_{\max }} k T_{S}|\Delta f(k)| \\
I T A E_{2} & =\sum_{k=1}^{N_{\max }} k T_{s}\left|\Delta P_{e}(k)\right| \\
I S E_{1} & =\sum_{k=1}^{N_{\max }}(\Delta f(k))^{2} \\
\text { ISE } & =\sum_{k=1}^{N_{\max }}\left(\Delta P_{e}(k)\right)^{2} \\
I T S E_{1} & =\sum_{k=1}^{N_{\max }} k T_{S}(\Delta f(k))^{2} \\
\operatorname{ITSE}_{2} & =\sum_{k=1}^{N_{\max }} k T_{S}\left(\Delta P_{e}(k)\right)^{2}
\end{aligned}
$$

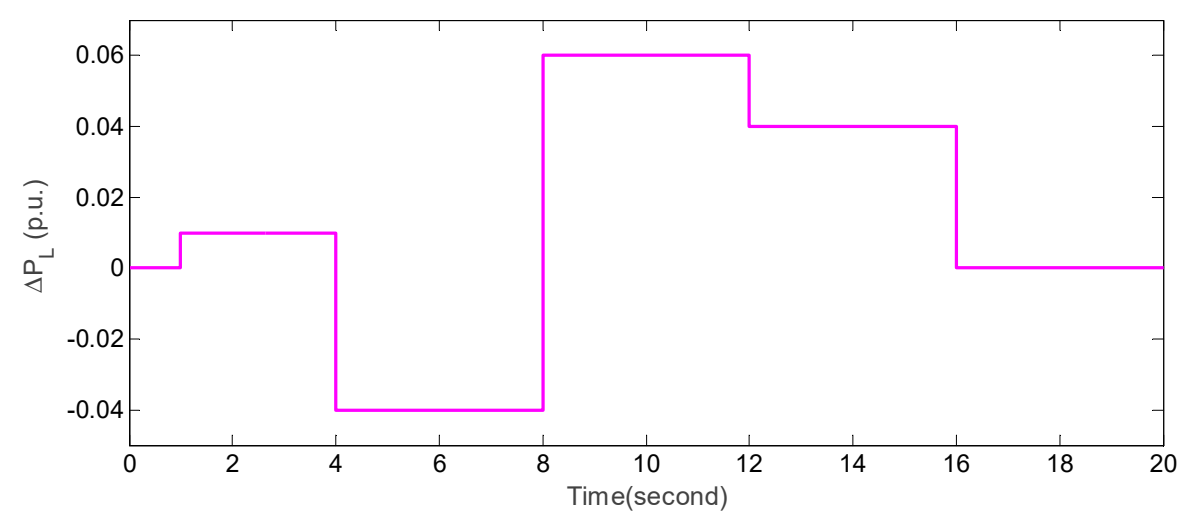

(a) $\Delta P_{L}$

Figure 5. Cont. 


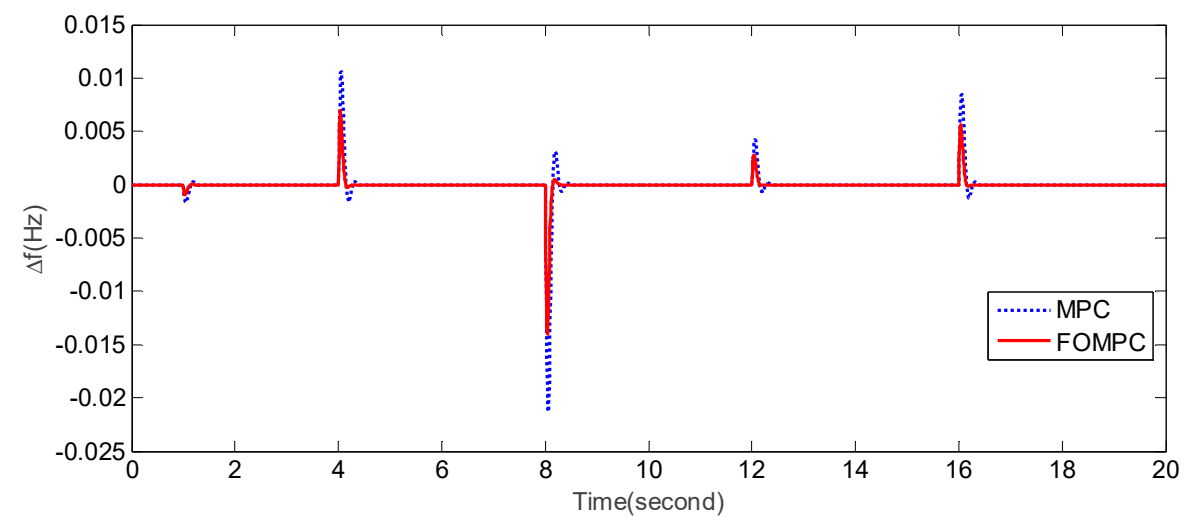

(b) $\Delta f$

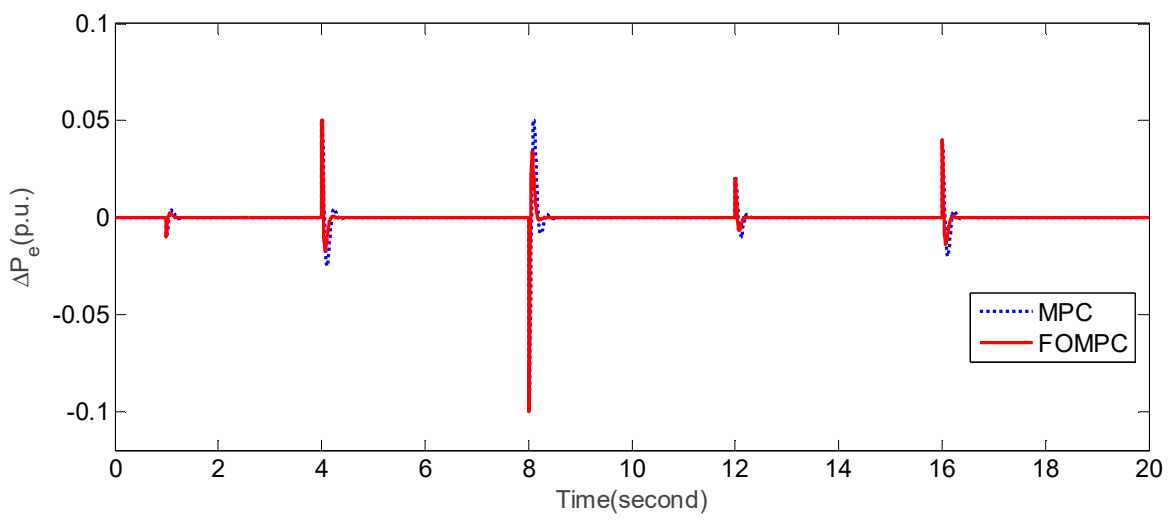

(c) $\triangle P_{e}$

Figure 5. Responses of $\Delta f$ and $\Delta P_{e}$ by FOEMPC and MPC under case 2.

Table 5 also shows the control performance indices obtained by FOMPC and MPC for an islanded microgrid under case 2. Obviously, all the indices obtained by FOMPC are better than those by MPC 23 .

Table 5. Performance comparison of FOMPC and MPC for an islanded microgrid under case 2. The best values are marked in bold.

\begin{tabular}{|c|c|c|c|c|c|c|c|c|}
\hline Algorithm & $I A E_{1}$ & $I T A E_{1}$ & $I S E_{1}$ & $I T S E_{1}$ & $I A E_{2}$ & $I T A E_{2}$ & $I S E_{2}$ & $I T S E_{2}$ \\
\hline MPC & 0.4704 & 4.1198 & 0.0045 & 0.0378 & 2.6375 & 23.1068 & 0.0920 & 0.7645 \\
\hline FOEMPC & 0.2276 & 1.9946 & 0.0015 & 0.0127 & 1.6009 & 14.0405 & 0.0605 & 0.5020 \\
\hline
\end{tabular}

\subsection{Case 3: Normal System Parameters and Random Dynamical Fluctuations of $\Delta w$}

In case 3, we designed an experiment under normal system parameters and random dynamical fluctuations of $\Delta w$ shown in Figure 6a. It should be noted that the random dynamical fluctuations of $\Delta w$ are modeled based on Reference [34]. Figure $6 \mathrm{~b}, \mathrm{c}$ compares $\Delta f$ and $\Delta P_{e}$ of FOMPC and MPC, respectively. Intuitively, the fluctuations of $\Delta f$ and $\Delta P_{e}$ obtained by FOMPC are also less than those by MPC [23]. From a quantitative perspective, Table 6 compares the performance indices, such as $I A E_{1}, I A E_{2}, I T A E_{1}, I T A E_{2}, I S E_{1}, I S E_{2}, I T S E_{1}$ and ITSE $E_{2}$ obtained by FOMPC and MPC. It is evident that FOMPC outperforms MPC under case 3. 


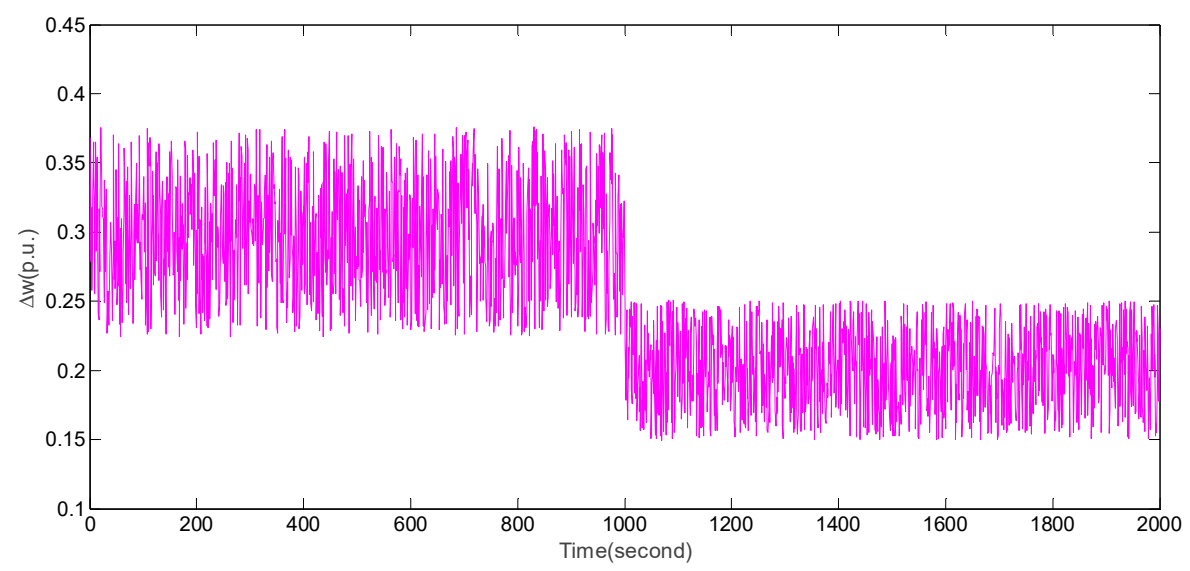

(a) $\Delta w$

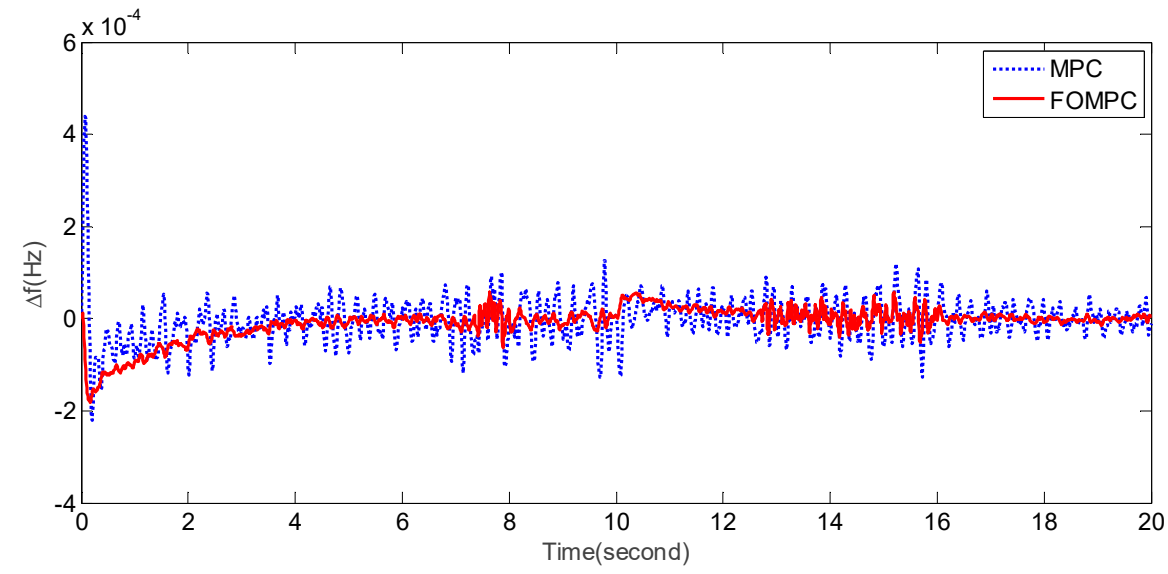

(b) $\Delta f$

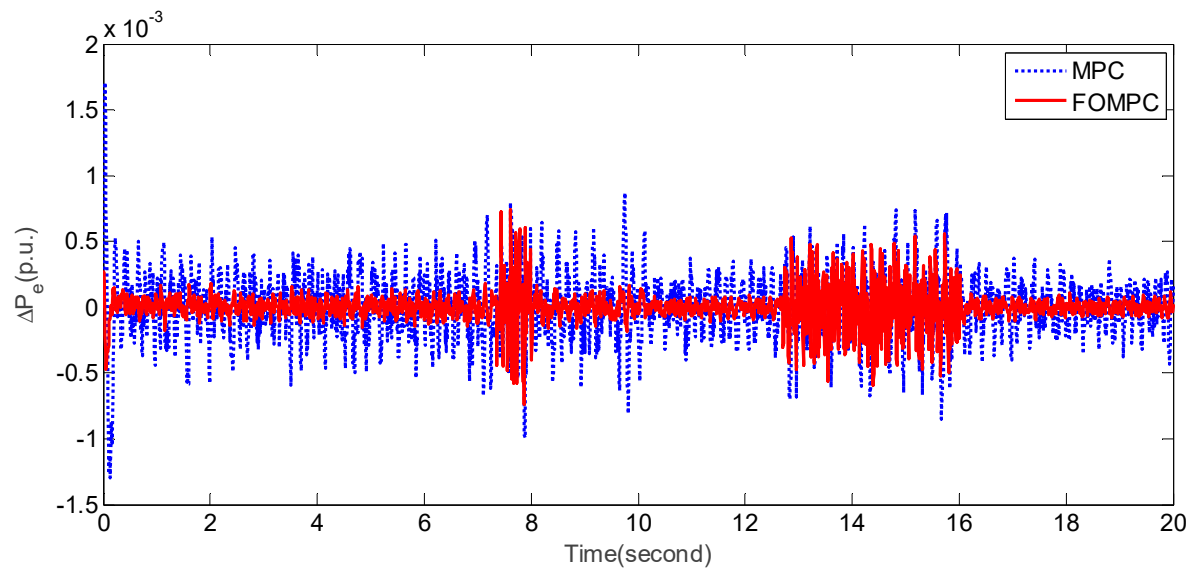

(c) $\triangle P_{e}$

Figure 6. Responses of $\Delta f$ and $\Delta P_{e}$ by FOEMPC and MPC under case 3.

Table 6. Performance indices obtained by FOMPC and MPC for an islanded microgrid under case 3. The best values are marked in bold.

\begin{tabular}{|c|c|c|c|c|c|c|c|c|}
\hline Algorithm & $I A E_{1}$ & $I T A E_{1}$ & $I S E_{1}$ & $I T S E_{1}$ & $I A E_{2}$ & $I T A E_{2}$ & $I S E_{2}$ & $I T S E_{2}$ \\
\hline MPC & 0.3044 & 3.7000 & $1.84 \times 10^{5}$ & $2.04 \times 10^{4}$ & 2.2401 & 27.3855 & $7.50 \times 10^{4}$ & 0.0090 \\
\hline FOEMPC & 0.1454 & 1.5672 & $5.36 \times 10^{6}$ & $4.12 \times 10^{5}$ & 1.5521 & 19.4406 & $4.35 \times 10^{4}$ & 0.0054 \\
\hline
\end{tabular}


4.4. Case 4: Perturbed System Parameters and Dynamical $\Delta P_{L}$

In order to test the robustness of FOMPC and MPC against perturbed system parameters and dynamical $\Delta P_{L}$, we design an experiment under the following condition: $T_{t}=0.6$ (increase $50 \%$ ), $R=1.5$ (decrease 50\%), $H=0.0833$ (decrease $50 \%$ ), and dynamical fluctuations of $\Delta P_{L}$ (e.g., Figure 7a). Figure $7 \mathrm{~b}, \mathrm{c}$ present the responses of $\Delta f$ and $\Delta P_{e}$ by FOMPC and MPC, respectively. It is apparent that the responses of $\Delta f$ and $\Delta P_{e}$ obtained by FOMPC are better than those by MPC because of its more smooth flucutations and faster stabilization. Furthermore, the corresponding comparison of $I A E_{1}$, $I A E_{2}, I T A E_{1}, I T A E_{2}, I S E_{1}, I S E_{2}, I T S E_{1}$, and ITSE 2 is shown in Table 7. It is obvious that the proposed FOMPC method is superior to the traditional MPC [23] under case 4.

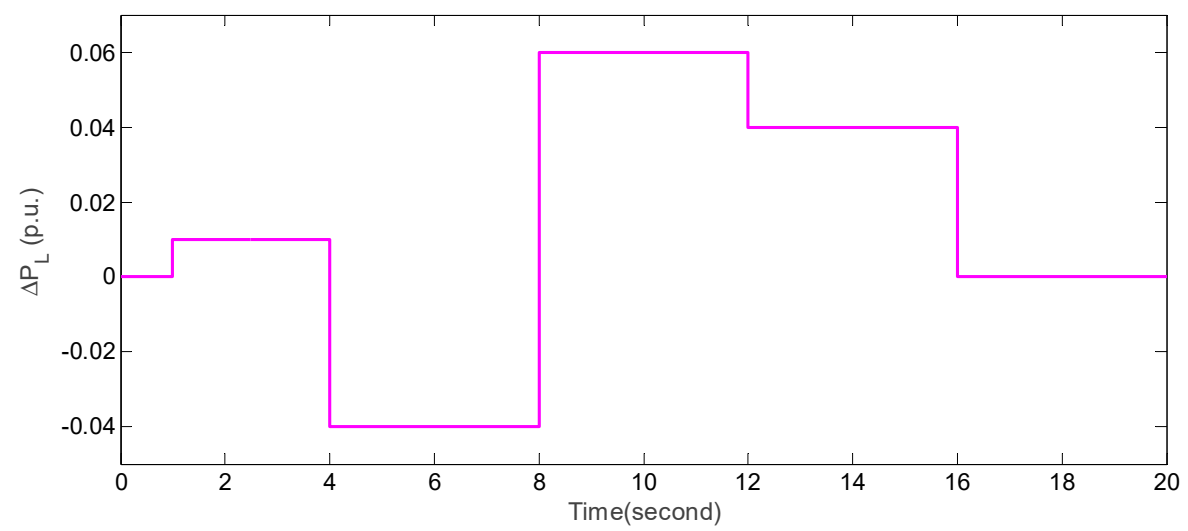

(a) $\triangle P_{L}$

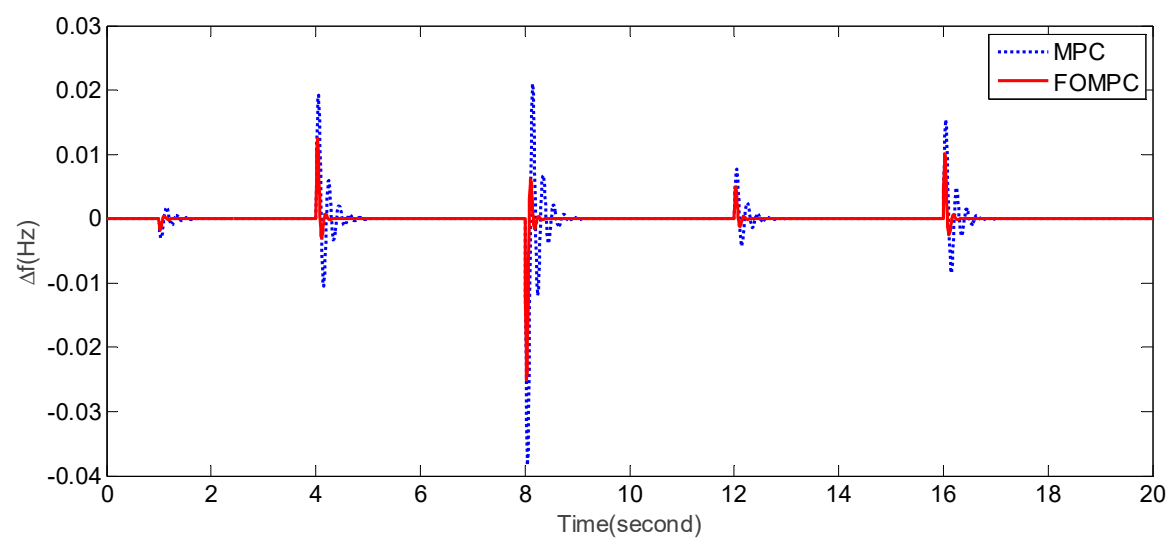

(b) $\Delta f$

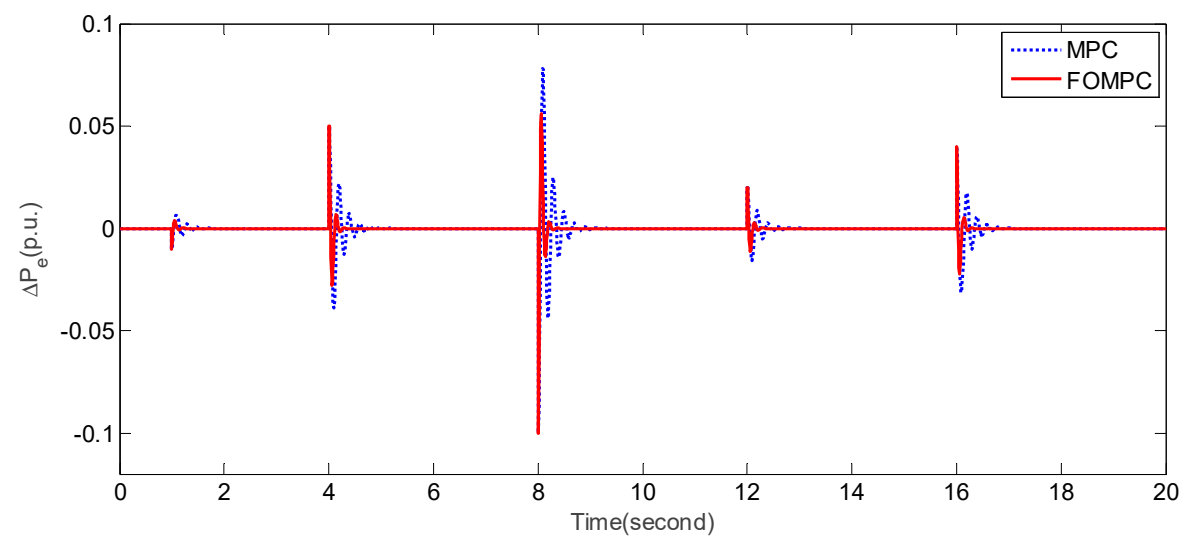

(c) $\triangle P \mathrm{e}$

Figure 7. Reponses of $\Delta f$ and $\Delta P_{\mathrm{e}}$ by FOMPC and MPC under case 4 . 
Table 7. Performance indices obtained by FOMPC and MPC for an islanded microgrid under case 4. The best values are marked in bold.

\begin{tabular}{ccccccccc}
\hline Algorithm & $\boldsymbol{I A E}_{\mathbf{1}}$ & $\boldsymbol{I T A E}_{\mathbf{1}}$ & $\boldsymbol{I S E}_{\mathbf{1}}$ & $\boldsymbol{I T S E}_{\mathbf{1}}$ & $\boldsymbol{I A E}_{\mathbf{2}}$ & $\boldsymbol{I T A E}_{\mathbf{2}}$ & $\boldsymbol{I S E}_{\mathbf{2}}$ & $\boldsymbol{I T S E}_{\mathbf{2}}$ \\
\hline MPC & 1.2148 & 10.7375 & 0.0157 & 0.1312 & 4.7186 & 41.6843 & 0.1417 & 1.1831 \\
FOEMPC & $\mathbf{0 . 3 4 8 1}$ & $\mathbf{3 . 0 5 2 3}$ & $\mathbf{0 . 0 0 3 7}$ & $\mathbf{0 . 0 3 0 7}$ & $\mathbf{1 . 8 9 2 7}$ & $\mathbf{1 6 . 6 0 4 1}$ & $\mathbf{0 . 0 6 9 9}$ & $\mathbf{0 . 5 8 0 1}$ \\
\hline
\end{tabular}

\subsection{Case 5: Perturbed System Parameters and Random Dynamical Fluctuations of $\Delta w$}

For case 5, we consider the condition of perturbed system parameters, e.g., $T_{t}=0.6$ (increase 50\%), $R=1.5$ (decrease 50\%), $H=0.0833$ (decrease 50\%), and random dynamical fluctuations of $\Delta \mathrm{w}$ shown in Figure 8a. Figure 8b,c compare $\Delta f$ and $\Delta P_{e}$ obtained by FOMPC and MPC under case 5 , respectively. It is obvious that these fluctuations of $\Delta f$ and $\Delta P_{e}$ obtained by FOMPC are less than MPC. Additionally, Table 8 also shows the comparison of the aforementioned eight indices. Clearly, the eight peformance indices of FOMPC are all better than those by MPC [23]. In other words, FOMPC is more robust than MPC under case 5 .

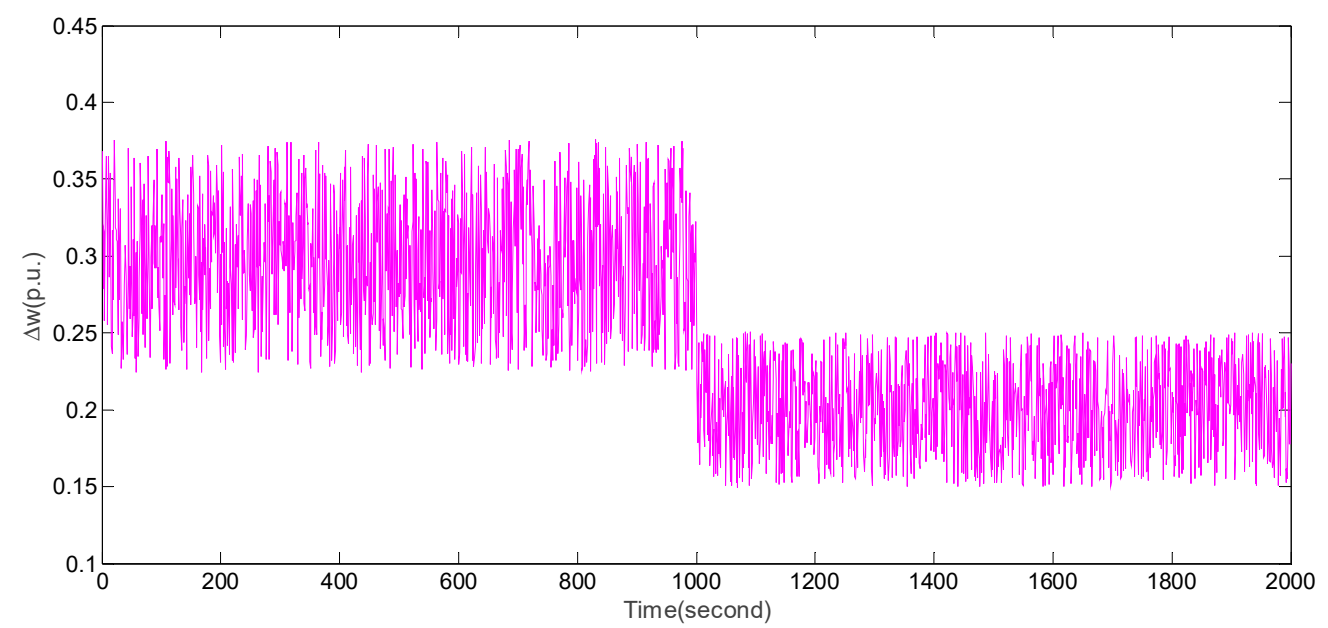

(a) $\Delta w$

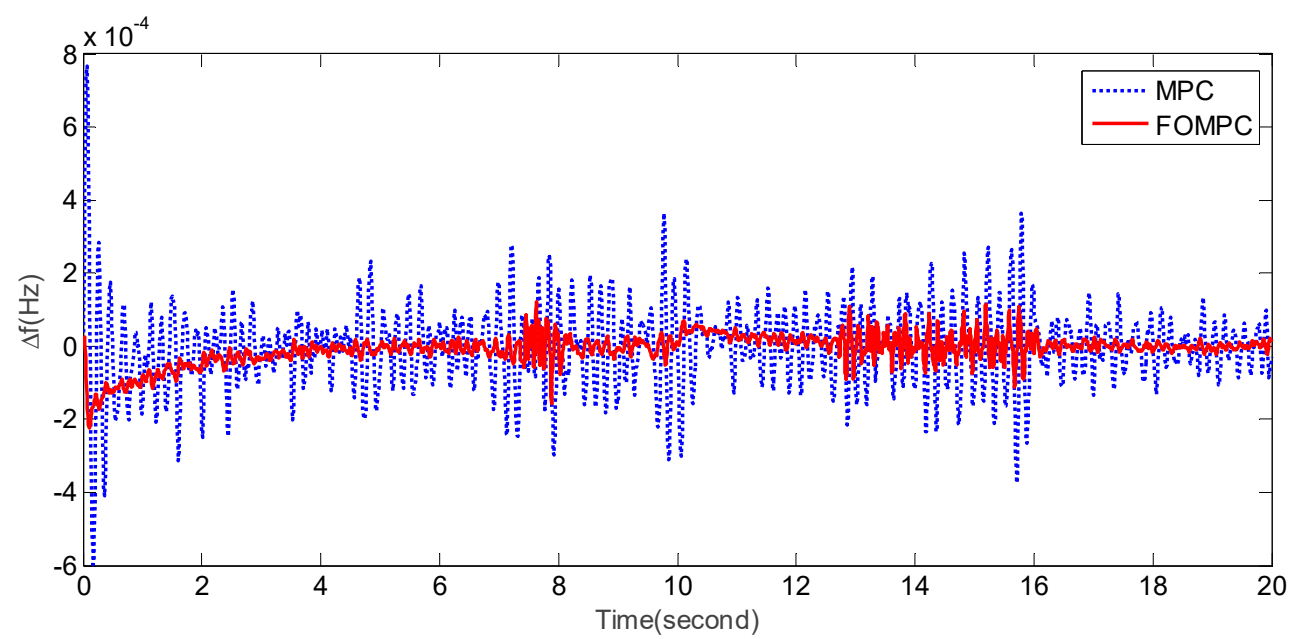

(b) $\Delta f$

Figure 8. Cont. 


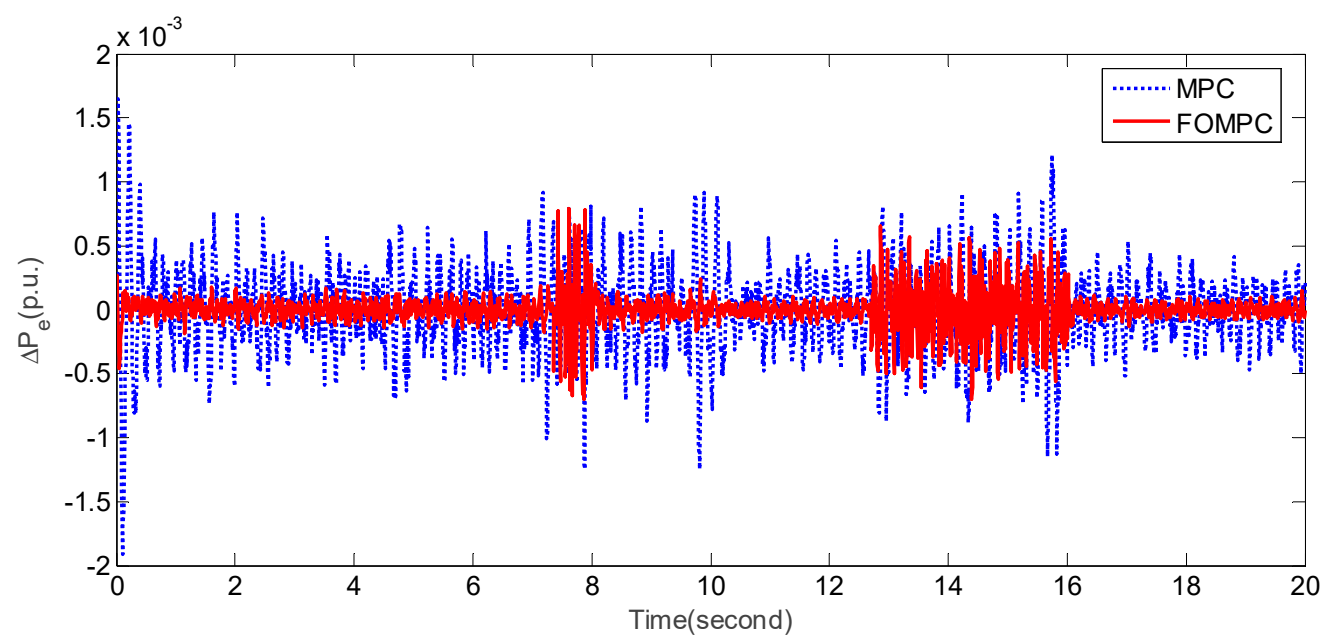

(c) $\triangle P_{e}$

Figure 8. Responses of $\Delta f$ and $\Delta P_{\mathrm{e}}$ by FOMPC and MPC under case 5.

Table 8. Performance indices obtained by FOMPC and MPC for an islanded microgrid under case 5. The best values are marked in bold.

\begin{tabular}{ccccccccc}
\hline Algorithm & IAE $_{\mathbf{1}}$ & ITAE $_{\mathbf{1}}$ & ISE $_{\mathbf{1}}$ & ITSE $_{\mathbf{1}}$ & IAE $_{\mathbf{2}}$ & ITAE $_{\mathbf{2}}$ & ISE $_{\mathbf{2}}$ & ITSE $_{\mathbf{2}}$ \\
\hline MPC & 0.8047 & 10.1467 & $1.28 \times 10^{4}$ & 0.0016 & 3.4273 & 42.6849 & 0.0015 & 0.0182 \\
FOEMPC & $\mathbf{0 . 2 6 7 4}$ & $\mathbf{3 . 1 1 4 4}$ & $\mathbf{1 . 5 4} \times \mathbf{1 0}^{\mathbf{5}}$ & $\mathbf{0 . 0 0 0 2}$ & $\mathbf{1 . 7 7 4 5}$ & $\mathbf{2 2 . 2 5 5 8}$ & $\mathbf{0 . 0 0 0 5}$ & $\mathbf{0 . 0 0 6 4}$ \\
\hline
\end{tabular}

\subsection{Case 6: The Worst Case}

In case 6 , we consider the worst case, i.e., under the following combined condition: $T_{t}=0.6$ (increase $50 \%$ ), $R=1.5$ (decrease $50 \%$ ), $H=0.0833$ (decrease 50\%), dynamical fluctuations of $\Delta P_{L}$ shown in Figure 9a, and random dynamical fluctuations of $\Delta \mathrm{w}$ shown in Figure $9 \mathrm{~b}$. For case 6, Figure 9c,d show the reponses of $\Delta f$ and $\Delta P_{e}$ by FOMPC and MPC, respectively. Obviously, It is apparent that the fluctuations of $\Delta f$ and $\Delta P_{e}$ by FOMPC are also more smooth than those by MPC even under the worst case. Moreover, Table 9 compares the corresponding performance indices obtained by FOMPC and MPC. Clearly, FOMPC performs better than MPC in terms of all the indices, which indicates that FOMPC has better robustness than the traditional MPC [23] under the worst case.

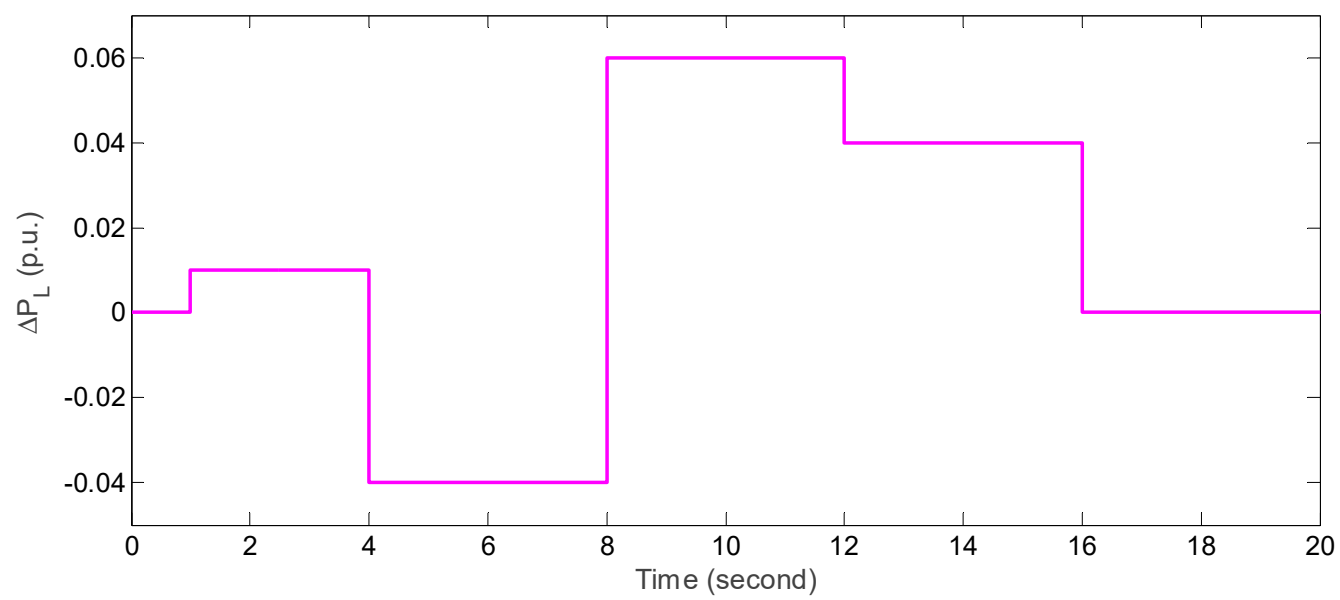

(a) $\Delta P_{L}$

Figure 9. Cont. 


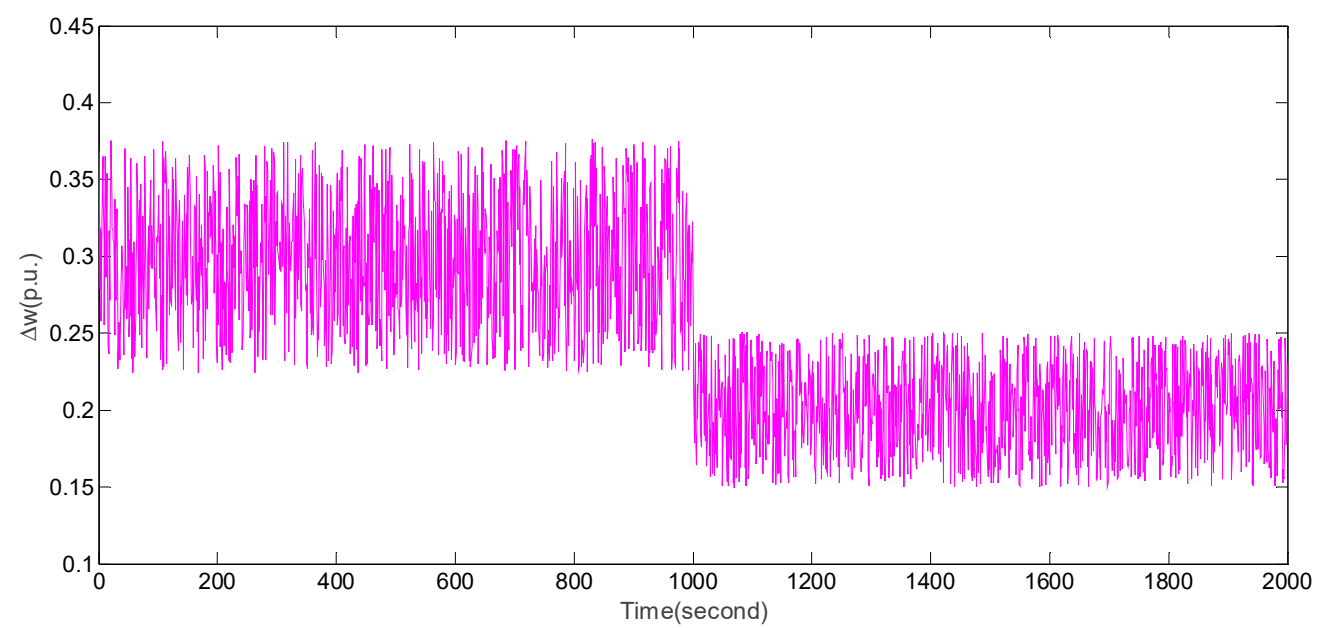

(b) $\Delta w$

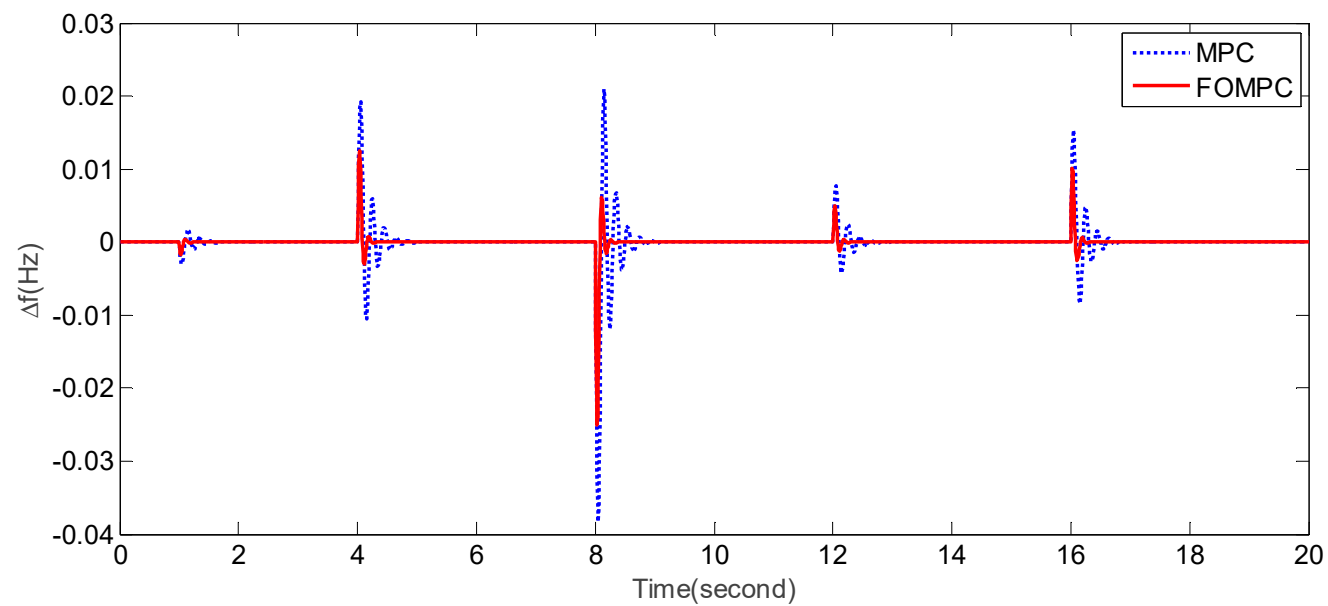

(c) $\Delta f$

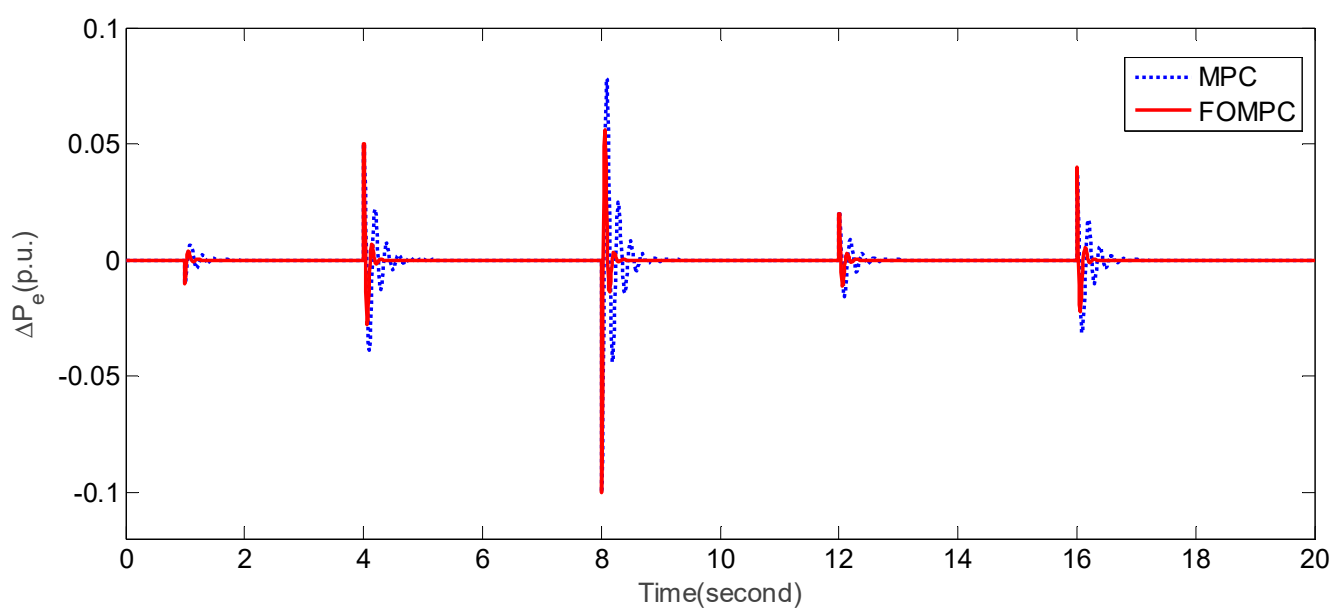

(d) $\Delta P_{e}$

Figure 9. Dynamical responses of $\Delta f$ and $\Delta P_{\mathrm{e}}$ obtained by FOMPC and MPC under case 6. 
Table 9. Performance indices obtained by FOMPC and MPC for an islanded microgrid under case 6. The best values are marked in bold.

\begin{tabular}{ccccccccc}
\hline Algorithm & $I A E_{\mathbf{1}}$ & $I T A E_{\mathbf{1}}$ & ISE $_{\mathbf{1}}$ & ITSE $_{\mathbf{1}}$ & IAE $_{\mathbf{2}}$ & ITAE $_{\mathbf{2}}$ & ISE $_{\mathbf{2}}$ & ITSE $_{\mathbf{2}}$ \\
\hline MPC & 2.0268 & 20.8613 & 0.0163 & 0.1366 & 13.2341 & 135.7164 & 0.5758 & 5.0990 \\
FOEMPC & $\mathbf{0 . 6 5 6 3}$ & $\mathbf{6 . 5 3 5 7}$ & $\mathbf{0 . 0 0 4 2}$ & $\mathbf{0 . 0 3 5 1}$ & $\mathbf{8 . 8 8 3 2}$ & $\mathbf{9 1 . 6 7 2 2}$ & $\mathbf{0 . 5 0 5 6}$ & $\mathbf{4 . 5 1 1 5}$ \\
\hline
\end{tabular}

\subsection{The Effects of Fractional-Order Parameters on Frequency Control Performance}

As the aforementioned description of the FOMPC method in Section 3, fractional-order parameters $\beta$ and $\gamma$ play important roles in adjusting the frequency control performance. To illustrate the effects of $\beta$ and $\gamma$ on the frequency control performance, Figure 10 presents the frequency deviation $\Delta f$ under a set of different values for $\beta$ and $\gamma$. Intuitively, the dynamical responses become faster, and the steady-state performance becomes better as the values of $\beta$ and $\gamma$ increase.

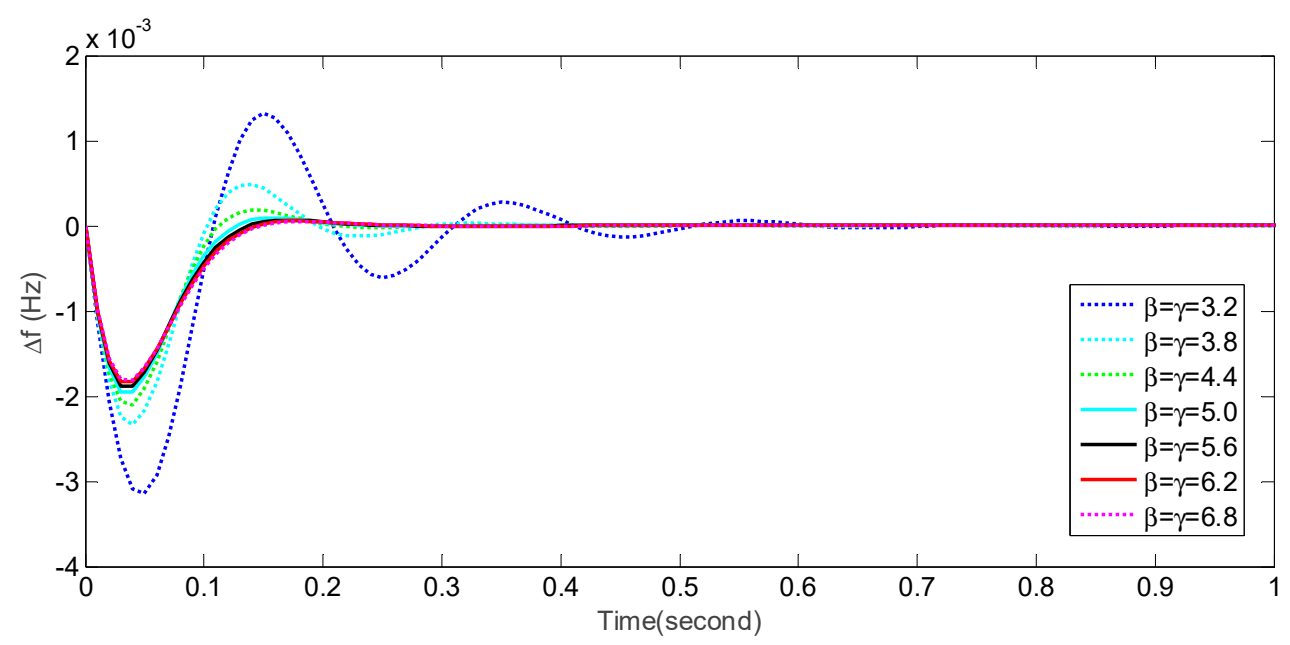

Figure 10. Effects of fractional-order parameters on the frequency control performance of an islanded microgrid.

\section{Conclusions and Open Issues}

In this work, a novel FOMPC-based optimal frequency control method is designed for an islanded microgrid. The proposed FOMPC method has extended the traditional quadratic cost function and introduced a fractional-order integral cost function based on the GL fractional-order integral definition. Simulation results have demonstrated the superiority of FOMPC to conventional MPC [23] with integer-order cost function under dynamical load disturbances, perturbed system parameters and random dynamical power fluctuation of wind turbines. Moreover, this paper discussed the effects of two important fractional-order parameters used in the FOMPC method on frequency control performance. In conclusion, the FOMPC method can be considered as a promising solution for the optimal frequency control issue of an islanded microgrid. Nevertheless, some of the following open issues are still rather remarkable for future research. Firstly, the fractional-order calculus theory can also be introduced into the gradient descent method used in FOMPC. Secondly, it is still challenging to tune a set of optimal algorithm parameters used in FOMPC from the multi-objective optimization perspective. Furthermore, the extension of the proposed FOMPC to more complex power systems is another interesting research issue.

Author Contributions: M.-R.C. provided the basic idea and developed the framework of new method; G.-Q.Z. implemented the control algorithms, designed the simulation experiments, and prepared manuscript; K.D.L. implemented the simulation experiments; Y.X.D. analyzed the simulation results; D.-Q.B. revised the manuscript and improved the language. 
Funding: This work was funded by National Natural Science Foundation of China (No. 61872153), Natural Science Foundation of Guangdong Province (No. 2018A030313318), and Zhejiang Provincial Natural Science Foundation of China (Grant Nos. LY16F030011 and LZ16E050002).

Acknowledgments: The authors the anonymous referees and editors for valuable comments and suggestions to improve this paper.

Conflicts of Interest: The authors declare no conflict of interest.

\section{Nomenclature}

$\Delta f$

$\Delta u$

$\Delta w$

$\Delta P_{g}$

$\Delta P_{L}$

$\Delta P_{m}$

$\Delta P_{e}$

$D$

$E_{s s 1}\left(E_{s s 2}\right)$

$H$

$I A E_{1}\left(I A E_{2}\right)$

$I S E_{1}\left(I S E_{2}\right)$

$I T A E_{1}\left(I T A E_{2}\right)$

$\operatorname{ITSE}_{1}\left(\mathrm{ITSE}_{2}\right)$

$J(k)$

$J_{F O}(k)$

$M$

$M_{p 1}$

$M_{p 2}$

$N_{\max }$

$N_{u}$

$N_{w}$

$N_{x}$

$N_{y}$

$P$

$R$

$T_{e}$

$T_{g}$

$T_{W}$

$T_{S}$

$T_{t}$

$t_{u 1}$

$t_{u 2}$

$t_{s 1}$

$t_{s 2}$

$\Delta \mathbf{U}$

$\Delta \mathbf{W}$

$\Delta \mathbf{u}$

$\Delta \mathbf{u}_{\min }$

$\Delta \mathbf{u}_{\max }$

$\mathbf{A}_{c}$

$\mathbf{A}_{d}$
Frequency deviation of an islanded microgrid

Incremental form of control signal

Input power fluctuation of wind turbine generator

Power deviation of governor

Load fluctuation

Power deviation of turbine

Power deviation of an islanded mircogrid

Equivalent damping parameter of an islanded mircogrid

Steady-state error of $\Delta f\left(\Delta P_{e}\right)$

Inertia constant of microgrid

Integral of absolute error for $\Delta f\left(\Delta P_{e}\right)$

Integral of square error for $\Delta f\left(\Delta P_{e}\right)$

Integral of time multiplied absolute error for $\Delta f\left(\Delta P_{e}\right)$

Integral of time multiplied square error for $\Delta f\left(\Delta P_{e}\right)$

Integer-order cost function of the predictive model

Fractional-order integral cost function of the predictive model

Control horizon

Overshoot of $\Delta f$

Overshoot of $\Delta P_{e}$

Maximum number of sampling times

Dimension of $\mathbf{u}$

Dimension of $\mathbf{w}$

Dimension of $\mathbf{x}$

Dimension of $\mathbf{y}$

Prediction horizon

Speed droop constant

Inertial time constant of energy storage system

Inertial time constant of governor

Inertial time constant of wind turbine generator

Sampling period

Inertial time constant of turbine

Rising time of $\Delta f$

Rising time of $\Delta P_{e}$

Settling time of $\Delta f$

Settling time of $\Delta P_{e}$

Predictive control vector

Predictive disturbance vector

Incremental vector of $\mathbf{u}$

Lower limits of $\Delta \mathbf{u}$

Upper limits of $\Delta \mathbf{u}$

Continuous-time form of system matrix

Discrete-time form of system matrix 


$\begin{array}{ll}\mathbf{B}_{c 1} & \text { Continuous-time form of control matrix } \\ \mathbf{B}_{c 2} & \text { Continuous-time form of disturbance matrix } \\ \mathbf{B}_{d 1} & \text { Discrete-time form of control matrix } \\ \mathbf{B}_{d 2} & \text { Discrete-time form of disturbance matrix } \\ \mathbf{C} & \text { Continuous-time form of system output matrix } \\ \mathbf{C}_{d} & \text { Discrete-time form of system output matrix } \\ \mathbf{E} & \text { Predictive disturbance matrix } \\ \mathbf{F} & \text { Control matrix for the }(k-1) \text {-th sampling time } \\ \mathbf{G} & \text { Predictive system matrix } \\ \mathbf{H} & \text { Predictive incremental control matrix } \\ \mathbf{I} & \text { Identity matrix } \\ \mathbf{Q} & \text { Weight vector for predicted errors } \\ \mathbf{R} & \text { Weight vector for future control } \\ \mathbf{Y}_{P} & \text { Predictive output vector } \\ \mathbf{Y}_{r} & \text { Reference predictive vector } \\ \mathbf{c} & \text { Set-point vector of system output } \\ \mathbf{u} & \text { Control vector } \\ \mathbf{u}_{\min } & \text { Lower limits of } \mathbf{u} \\ \mathbf{u}_{\max } & \text { Upper limits of } \mathbf{u} \\ \mathbf{w} & \text { Disturbance vector } \\ \mathbf{x} & \text { State vector } \\ \mathbf{y} & \text { System output vector } \\ \mathbf{y}(k+p \mid k) & \text { The }(k+p) \text {-th predictive output at } k \text {-th sampling time } \\ \mathbf{y}_{\min } & \text { Lower limits of } \mathbf{y} \\ \mathbf{y}_{\max } & \text { Upper limits of } \mathbf{y} \\ \mathbf{y}_{\mathbf{r}}(k+p \mid k) & \text { The }(k+p) \text {-th predictive reference vector at } k \text {-th sampling time } \\ \beta & \text { Fractional-order parameter used in square future control } \\ \gamma & \text { Fractional-order parameter used in square predicted errors } \\ \eta & \text { Soften factor } \\ & \end{array}$

\section{References}

1. Sen, S.; Kumar, V. Microgrid modelling: A comprehensive survey. Annu. Rev. Control 2018, 46, $216-250$. [CrossRef]

2. Alam, M.N.; Chakrabarti, S.; Ghosh, A. Networked microgrids: State-of-the-art and future prospectives. IEEE Trans. Ind. Inform. 2018. [CrossRef]

3. Kumar, J.; Agarwal, A.; Agarwal, V. A review on overall control of DC microgrids. J. Energy Storage 2019, 21, 113-138. [CrossRef]

4. Zhang, L.; Tang, Y.; Yang, S.; Gao, F. Decoupled power control for a modular-multilevel-converter-based hybrid AC-DC grid integrated with hybrid energy storage. IEEE Trans. Ind. Electron. 2019, 66, 2926-2934. [CrossRef]

5. Chen, M.R.; Wang, H.; Zeng, G.Q.; Dai, Y.X.; Bi, D.Q. Optimal PQ Control of grid-connected inverters in a microgrid based on adaptive population extremal optimization. Energies 2018, 11, 2107. [CrossRef]

6. Deng, Z.; Xu, Y.; Sun, H.; Shen, X. Distributed, bounded and finite-time convergence secondary frequency control in an autonomous microgrid. IEEE Trans. Smart Grid 2018. [CrossRef]

7. Lal, D.K.; Barisal, A.K.; Tripathy, M. Load frequency control of multi area interconnected microgrid power system using grasshopper optimization algorithm optimized fuzzy PID controller. In Proceedings of the 2018 Recent Advances on Engineering, Technology and Computational Sciences (RAETCS), Allahabad, India, 6-8 February 2018; pp. 1-6.

8. Yang, T.; Zhang, Y.; Wang, Z.; Peng, H. Secondary frequency stochastic optimal control in independent microgrids with virtual synchronous generator-controlled energy storage systems. Energies 2018, 11, 2388. [CrossRef] 
9. Barik, A.K.; Das, D.C. Expeditious frequency control of solar photovoltaic/biogas/biodiesel generator based isolated renewable microgrid using grasshopper optimisation algorithm. IET Renew. Power Gener. 2018, 12, 1659-1667. [CrossRef]

10. Dong, L.; Wang, H.; Zeng, G.Q.; Zhang, Z.Z.; Wu, L.; Xiong, R.; Dai, Y.X. Optimal droop control of distributed inverters in a microgrid under autonomous mode based on differenial evolution. In Proceedings of the 2018 Chinese Automation Congress, Xi'an, China, 30 November-2 December 2018.

11. Zhang, R.D.; Xue, A.K.; Gao, F.R. Model Predictive Control; Springer: Singapore, 2019.

12. Pahasa, J.; Ngamroo, I. Coordinated PHEV, PV, and ESS for microgrid frequency regulation using centralized model predictive control considering variation of PHEV number. IEEE Access 2018, 6, 69151-69161. [CrossRef]

13. Guo, Z.; Li, S.; Zheng, Y. Feedback linearization based distributed model predictive control for secondary control of islanded microgrid. Asian J. Control 2020, 22, 1-14. [CrossRef]

14. Chen, M.R.; Zeng, G.Q.; Xie, X.Q. Population extremal optimization-based extended distributed model predictive load frequency control of multi-area interconnected power systems. J. Frankl. Inst. 2018, 355, 8266-8295. [CrossRef]

15. Charles, K.; Urasaki, N.; Senjyu, T.; Elsayed Lotfy, M.; Liu, L. Robust load frequency control schemes in power system using optimized PID and model predictive controllers. Energies 2018, 11, 3070. [CrossRef]

16. Sun, B.; Tang, Y.; Ye, L.; Chen, C.; Zhang, C.; Zhong, W. A frequency control strategy considering large scale wind power cluster integration based on distributed model predictive control. Energies 2018, 11, 1600. [CrossRef]

17. Xing, X.; Xie, L.; Meng, H. Cooperative energy management optimization based on distributed MPC in grid-connected microgrids community. Int. J. Electr. Power Energy Syst. 2019, 107, 186-199. [CrossRef]

18. Olama, A.; Mendes, P.R.C.; Camacho, E.F. Lyapunov-based hybrid model predictive control for energy management of microgrids. IET Gener. Transm. Distrib. 2018, 12, 5770-5780. [CrossRef]

19. Hans, C.A.; Sopasakis, P.; Raisch, J.; Reincke-Collon, C.; Patrinos, P. Risk-averse model predictive operation control of islanded microgrids. arXiv, 2018; arXiv:1809.06062.

20. Yanan, W.; Jiekang, W.; Mao, X. Intelligent scheduling optimization of seasonal CCHP system using rolling horizon hybrid optimization algorithm and matrix model framework. IEEE Access 2018, 6, 75132-75142. [CrossRef]

21. Kayalvizhi, S.; Kumar, D.M.V. Load frequency control of an isolated microgrid using fuzzy adaptive model predictive control. IEEE Access 2017, 5, 16241-16251. [CrossRef]

22. Wang, H.; Yang, J.; Chen, Z.; Ge, W.; Ma, Y.; Xing, Z.; Yang, L. Model predictive control of PMSG-based wind turbines for frequency regulation in an isolated grid. IEEE Trans. Ind. Appl. 2018, 54, 3077-3089. [CrossRef]

23. Nguyen, T.T.; Yoo, H.J.; Kim, H.M. Analyzing the impacts of system parameters on MPC-based frequency control for a stand-alone microgrid. Energies 2017, 10, 417. [CrossRef]

24. Monje, C.A.; Chen, Y.Q.; Vinagre, B.M.; Xue, D.; Feliu-Batlle, V. Fractional-Order Systems and Controls: Fundamentals and Applications; Springer Science \& Business Media: New York, NY, USA, 2010.

25. Ren, H.P.; Fan, J.T.; Kaynak, O. Optimal design of a fractional order PID controller for a pneumatic position servo system. IEEE Trans. Ind. Electron. 2018. [CrossRef]

26. Liu, W.; Bian, G.B.; Rahman, M.R.U.; Zhang, H.; Chen, H.; Wu, W. Fractional-order PID servo control based on decoupled visual model. Int. J. Adapt. Control Signal Process. 2018. [CrossRef]

27. Radac, M.B.; Precup, R.E. Data-driven MIMO model-free reference tracking control with nonlinear state-feedback and fractional order controllers. Appl. Soft Comput. 2018, 73, 992-1003. [CrossRef]

28. Zhou, K.; Tai, Y.; Chen, N. Fractional order PID control of two-wheel electric balance vehicle. In Proceedings of the 2018 Chinese Control and Decision Conference (CCDC), Shenyang, China, 9-11 June 2018; pp. 878-882.

29. Saleem, A.; Soliman, H.; Al-Ratrout, S.; Mesbah, M. Design of a fractional order PID controller with application to an induction motor drive. Turk. J. Electr. Eng. Comput. Sci. 2018, 26, 2768-2778. [CrossRef]

30. Yang, B.; Yu, T.; Shu, H.; Han, Y.; Cao, P.; Jiang, L. Adaptive fractional-order PID control of PMSG-based wind energy conversion system for MPPT using linear observers. Int. Trans. Electr. Energy Syst. 2018. [CrossRef]

31. Zeng, G.Q.; Chen, J.; Dai, Y.X.; Li, L.M.; Zheng, C.W.; Chen, M.R. Design of fractional order PID controller for automatic regulator voltage system based on multi-objective extremal optimization. Neurocomputing 2015, 160, 173-184. [CrossRef] 
32. Çelik, V.; Özdemir, M.T. Effects of fractional-order PI controller on delay margin in single-area delayed load frequency control systems. J. Mod. Power Syst. Clean Energy 2018. [CrossRef]

33. Mohammadikia, R.; Aliasghary, M. A fractional order fuzzy PID for load frequency control of four-area interconnected power system using biogeography-based optimization. Int. Trans. Electr. Energy Syst. 2018. [CrossRef]

34. Wang, H.; Zeng, G.Q.; Dai, Y.X.; Bi, D.Q.; Sun, J.L.; Xie, X.Q. Design of fractional order frequency PID controller for an islanded microgrid: A multi-objective extremal optimization method. Energies 2017, 10, 1502. [CrossRef]

35. Romero, M.; Mañoso, C.; Ángel, P.; Vinagre, B.M. Fractional-order generalized predictive control: Formulation and some properties. In Proceedings of the 11th International Conference on Control Automation Robotics \& Vision (ICARCV), Singapore, 7-10 December 2010; pp. 1495-1500.

36. Romero, M.; de Madrid, A.P.; Mañoso, C.; Milanés, V.; Vinagre, B.M. Fractional-order generalized predictive control: Application for low-speed control of gasoline-propelled cars. Math. Probl. Eng. 2013, 2013, 895640. [CrossRef]

37. Bigdeli, N. The design of a non-minimal state space fractional-order predictive functional controller for fractional systems of arbitrary order. J. Process Control 2015, 29, 45-56. [CrossRef]

38. Sopasakis, P.; Ntouskas, S.; Sarimveis, H. Robust model predictive control for discrete-time fractional-order systems. In Proceedings of the 23th Mediterranean Conference on Control and Automation (MED), Torremolinos, Spain, 16-19 June 2015; pp. 384-389.

39. Sopasakis, P.; Sarimveis, H. Stabilising model predictive control for discrete-time fractional-order systems. Automatica 2017, 75, 24-31. [CrossRef]

40. Zhang, R.; Zou, Q.; Cao, Z.; Gao, F. Design of fractional order modeling based extended non-minimal state space MPC for temperature in an industrial electric heating furnace. J. Process Control 2017, 56, 13-22. [CrossRef]

41. Sanatizadeh, M.; Bigdeli, N. The design of a coprime-factorized predictive functional controller for unstable fractional order systems. Asian J. Control 2019. [CrossRef]

42. Ntouskas, S.; Sarimveis, H.; Sopasakis, P. Model predictive control for offset-free reference tracking of fractional order systems. Control Eng. Pract. 2018, 71, 26-33. [CrossRef]

43. Romero, M.; Madrid, A.P.; Vinagre, B.M. Arbitrary real-order cost functions for signals and systems. Signal Process. 2011, 91, 372-378. [CrossRef]

44. Das, S.; Pan, I.; Halder, K.; Das, S.; Gupta, A. LQR based improved discrete PID controller design via optimum selection of weighting matrices using fractional order integral performance index. Appl. Math. Model. 2013, 37, 4253-4268. [CrossRef]

45. Zou, Q.; Jin, Q.; Zhang, R. Design of fractional order predictive functional control for fractional industrial processes. Chemom. Intell. Lab. Syst. 2016, 152, 34-41. [CrossRef]

46. Bevrani, H. Robust Power System Frequency Control, 2nd ed.; Springer: Gewerbestrasse, Switzerland, 2014. 